\title{
Functional Analysis of Human MT and Related Visual Cortical Areas Using Magnetic Resonance Imaging
}

\author{
Roger B. H. Tootell, ${ }^{1}$ John B. Reppas, ${ }^{2}$ Kenneth K. Kwong, ${ }^{1}$ Rafael Malach, ${ }^{1}$ Richard T. Born, ${ }^{1}$ Thomas J. \\ Brady,' Bruce R. Rosen, ${ }^{1}$ and John W. Belliveau' \\ ${ }^{1}$ Massachusetts General Hospital NMR Center, Charlestown, Massachusetts 02129 and ${ }^{2}$ Harvard-MIT Division of \\ Health Sciences and Technology, Boston, Massachusetts 02115
}

\begin{abstract}
Using noninvasive functional magnetic resonance imaging (fMRI) techniques, we analyzed the responses in human area MT with regard to visual motion, color, and luminance contrast sensitivity, and retinotopy. As in previous PET studies, we found that area MT responded selectively to moving (compared to stationary) stimuli. The location of human MT in the present fMRI results is conslstent wlth that of MT in earlier PET and anatomical studies.

In addition we found that area MT has a much higher contrast sensitivity than that in several other areas, including primary visual cortex (V1). Functional MRI half-amplitudes in $V_{1}$ and MT occurred at approximately $15 \%$ and $1 \%$ luminance contrast, respectively. High sensitivity to contrast and motion in MT have been closely associated with magnocellular stream specialization in nonhuman primates.
\end{abstract}

Human psychophysics indicates that visual motion appears to diminish when moving color-varying stimuli are equated in luminance. Electrophysiological results from macaque MT suggest that the human percept could be due to decreases in firing of area MT cells at equiluminance. We show here that fMRI activity in human MT does in fact decrease at and near individually measured equiluminance.

Tests with visuotopically restricted stimuli in each hemifield produced spatial variations in fMRI activity consistent with retinotopy in human homologs of macaque areas $\mathrm{V} 1$, V2, V3, and VP. Such activity in area MT appeared much less retinotopic, as in macaque. However, it was possible to measure the interhemispheric spread of fMRI activity in human MT (half amplitude activation across the vertical meridian $=\sim 1^{\circ}$ ).

\footnotetext{
Received May 4, 1994; revised Oct. 18, 1994; accepted Oct. 20, 1994.

This study was supported by Grants EY07980, RO1 MH 50054, RO1 HL 39810, PO1 CA48729, the Human Frontiers Science Program, and the McDonnell-Pew Program in Cognitive Neuroscience. It would not have been possible without the comprehensive technical support and gracious environment of the MGH NMR Center. Especially helpful were Randall Benson, Inhn Raker Aiping Jiang, Chantal Stern, Hans Breiter, Mark Cohen, Richard O'Sullivan, and Terrence Campbell. Bill Kennedy helped make several figures. We are grateful for the willing and thoughtful cooperation of numerous subjects, especially Linda Kobierski, Alex Guimares, and Christine Konradi. We also thank Richard Andersen, Bard Geeselman, and Ralph Siegal for videotapes of visual stimuli. Patrick Cavanagh generously furnished software for calibrating and creating color-varying stimuli, and we thank him for helpful discussions about human color vision.

Correspondence should be sent to Dr. Roger Tootell, MGH NMR Center, 14913 th Street, Charlestown, MA 02129.

Copyright $(C) 1995$ Society for Neuroscience $0270-6474 / 95 / 153215-16 \$ 05.00 / 0$
}

[Key words: functional MRI, area MT, human visual cortex, motion perception, contrast sensitivity, color]

The cerebral cortex is well mapped in the macaque monkey, and a wealth of detail is known about the cortical connections, the single unit properties, and the functional organization of different areas. By comparison, very little is known about corresponding areas in human cerebral cortex, or even if they exist. In this respect, the state of human neuroscience research is indeed "backward" (Crick and Jones, 1993). Although research on monkey cortex is commonly justified as a model for that of man, little effort has gone into testing the limits or generality of the macaque model.

In visual cortex, the largest and most accurately mapped cortical region in macaque, one fundamental but controversial finding is that visual information is channeled along two general, parallel, information processing pathways (for reviews, see Maunsell, 1987; Maunsell and Newsome, 1987; DeYoe and Van Essen, 1988; Livingstone and Hubel, 1988; Martin, 1988; Zeki and Shipp, 1988; Desimone and Ungerleider, 1989; Felleman and Van Essen, 1991; Kaas and Garraghty, 1991; Goodale and Milner, 1992; Van Essen et al., 1992; Merigan and Maunsell, 1993). In this model, information about visual color and form are processed in a ventral stream of interconnected cortical areas, and information about visual motion and location are processed in a dorsal stream.

By homology, parallel visual pathways have been proposed in humans. PET studies (Lueck et al., 1989; Corbetta et al., 1990; Zeki et al., 1991; Watson et al., 1993) suggest the presence of separate cortical regions for the processing of color versus motion, which is consistent with the parallel pathways model. However, little else is known about such regions, because of limits on spatial and temporal resolution, as well as radiation dosage limits inherent in PET technology. The radiation dose limits in particular sharply restrict the amount of information that can be gained from a single individual.

Clinical studies (for reviews, see Damasio et al., 1990; Zeki, 1990, 1991) also suggest that color and motion are processed in different cortical loci. However, lesions in such studies arc difficult to interpret because they include fibers of passage, and have an unknown relationship to the actual cortical areas of interest. Recent anatomical studies (Burkhalter and Bernardo, 1989; Clarke and Miklossy, 1990; Hockfield et al., 1990; Horton and Hoyt, 1991; Tootell and Taylor, 1994) have furnished preliminary information about areas V2, V3, MT, and VP in humans, but most of visual cortex remains essentially ummapped.

Some caution is appropriate when generalizing from cortical 
maps in monkey to those in humans, because numerous differences in cortical organization are known to exist between different orders of nonhuman primates. Such differences include discrepancies in the topography or existence of different extrastriate visual areas (Burkhalter et al., 1986; Sereno and Allman, 1991; Kaas, 1993), differences in "parallel" columnar architecture (e.g., DeBruyn et al., 1993), and differences in single unit properties in presumably homologous areas (e.g., Zeki, 1980). These cortical differences are paralleled by perceptual differences between species in color vision, contrast sensitivity, acuity, and other dimensions (DeValois et al., 1974a-c; Jacobs 1977a,b; Jacobs et al., 1979).

Recently, magnetic resonance imaging (MRI) techniques were introduced that make it possible to clarify these and other unresolved quesions about the functional organization of human visual cortex. In an initial study, exogenous contrast agents were administered to reveal activity-dependent changes in blood flow (Belliveau et al., 1991). Subsequent work has exploited endogenous changes in magnetic susceptibility due to localized activity-dependent variations in blood flow and oxygenation (Kwong et al., 1992; Ogawa et al., 1992). The latter functional MRI (fMRI) technique is noninvasive and without known danger, so that a given subject can be scanned repeatedly to clarify or average small signals. Spatial resolution can be less than a millimeter (Frahm et al., 1993; Menon et al., 1993), and responses occur within a few seconds (Bandettini et al., 1992; Kwong et al., 1992).

Using fMRI techniques based on blood flow and oxygenation, we were able to obtain very detailed functional information from single cortical visual areas. Here we describe results from area MT, also known as V5 in humans and macaques. Abstracts of this work have appeared (Tootell et al., 1993a,b).

We targeted area MT for several reasons. (1) In monkeys, it is distinct from surrounding areas, both functionally and anatomically. (2) Monkey MT also marks the anatomical beginning of one branch of the parallel pathways, the chain of cortical areas apparently mediating motion perception and spatial localization. Similar evidence in man would support the idea of parallel human visual pathways. (3) Unlike many extrastriate cortical visual arcas, presumptive homologs of area MT exist in all primates tested, including prosimians (Allman et al., 1973), New World monkeys (Allman and Kaas, 1971; Felleman and Kaas, 1984; Krubitzer and Kaas, 1990) and Old World monkeys (e.g., Dubner and Zeki, 1971; Van Essen et al., 1981; Gattas and Gross, 1981; Maunsell and Van Essen, 1983a,b; Albright, 1984; Fioriani et al., 1989). Therefore, it is likely to be evolutionarily conserved and exist in man as well. (4) More is known about the receptive field properties of monkey MT cells than perhaps any other extrastriate cortical visual area; this allowed us to make detailed predictions about the behavior of a human MT. (5) Finally, there is now some anatomical (Clarke and Miklossy, 1990; Sereno and Allman, 1991; Tootell and Taylor, 1994) and PET (Lueck et al., 1989; Zeki et al., 1991; Watson et al., 1993) evidence on the location of presumptive MT in man, to which the present results can be compared.

\section{Materials and Methods}

Sixty-five scanning sessions were devoted entirely or primarily to area MT. Eighteen normal human subjects were scanned (1-15 times) in a 1.5 T GE scanner with echo planar imaging (Advanced NMR). The data base of this study included approximately 400,000 images.

Functional MRI sequences were obtained while subjects viewed specifically designed visual stimuli. Most data were obtained using either gradient echo $(\mathrm{GE}, \mathrm{TE}=50 \mathrm{msec}, \mathrm{TR}=2000 \mathrm{msec})$ or asymmetric spin echo (ASE; TE $=80 \mathrm{msec}$, TR $=2-3000 \mathrm{msec}$; Wismer et al., 1988; Baker et al., 1993) sequences. Voxel size was set for either $3 \times$ $3 \times 5-6 \mathrm{~mm}$ or $1.6 \times 1.6 \times 4 \mathrm{~mm}$ ("low" or "high" spatial resolution, respectively). High resolution scans were used when the immediate experimental goal was optimal localization, and low resolution scans were used when a more favorable signal-to-noise ratio, or a quicker image reconstruction, was required

To minimize the possibility of vascular artifact, major findings were confirmed using more flow-specific sequences. Usually this was a spin echo inversion recovery sequence $(\mathrm{TI}=1100 \mathrm{msec}, \mathrm{TE}=43 \mathrm{msec}$ ) (Kwong et al., 1992), although T2-weighted spin echo sequences with increased microvascular sensitivity (Fisel et al., 1991; Kwong et al., 1993; Weiskoff et al., 1993) were also used. High-resolution anatomic (T1) and flow-compensated sequences (to highlight the vasculature) were also obtained during each scanning session, so that the location of the functional patterns could be compared to the location of the gray matter and the major vessels.

A $5^{\prime \prime}$ surface coil was positioned slightly lateral to the occipital pole, resulting in increased signal sensitivity in that underlying hemisphere. Samples were taken from both right and left hemispheres, in different experiments, but no obvious functional lateralization was seen in any of the areas described here. Analysis of laterally placed areas such as MT was usually confined to the hemisphere underlying the surface coil. In some subjects, sequences were gated to the subject's EKG to reduce baseline noise. Many subjects also used a bite bar to stabilize head position.

Using low-resolution scans, $6 \mathrm{~mm}$ thick, adequate coverage of visual cortex was obtained with only five or six contiguous slices. When 4 $\mathrm{mm}$ thick, high-resolution scans were used, 7-10 contiguous slices were required to cover the same area of interest. The number of slices used was kept to a minimum, because extra slices decreased the number of images per slice that could be obtained in each scan, due to scanner memory limitations.

In approximately two-thirds of the scanning sessions, slices were oriented parallel with the calcarine fissure (see Fig. $1 A$ ). The advantages of this slice plane included the following: (1) fewer slices were required to completely cover areas V1 and MT; (2) eccentricity-dependent variations in V1 are most clear in this plane; (3) this scan plane is least prone to partial volume sampling, bccause MT (vicwed as an oval of gray matter) is usually oriented perpendicular to this scanning plane.

In remaining scans, slices were oriented near-coronally, perpendicular to the above plane (Fig. $1 B$ ). This scan plane was optimal for sampling activity in inferior and superior visual cortical areas, or inferior versus superior visual field representations. Furthermore, because this plane runs near-parallel to MT in most subjects, topographical variations across the area are also most clear in this plane.

Subjects lay on their backs, facing the ceiling of the bore. Stimuli were rear-projected onto a stimulus screen providing an activated visual field $92^{\circ}$ wide by $65^{\circ}$ high. The screen (Da-lite Corp.) was positioned inside the magnet, just rostral to the subject's jaw. A large mirror was interposed between, and oriented approximately $45^{\circ}$ to, the screen and the subject's line of sight, so that subjects looked directly up to see an image positioned al neck level. Stimuli were projected onto the screen by a SONY 2000 color LCD projector, through a collimating lens. Depending on the stimuli used, the projector was driven by either (1) a Macintosh computer, via a Radius interface (model 0355, Videovision); (2) a videotape of visual stimuli, usually generated on a Silicon Graphics IRIS 3130; or (3) directly from a Silicon Graphics ONYX supercomputer.

Subjects were instructed to stare at a fixation spot at the center of the stimulus during MRI scans. Typically, four to six different stimulus periods (including as many different stimuli) were presented in a given 6 min scan, separated by control stimuli (uniform field of equal mean luminance, excepting the fixation spot) of equal duration. Most functional scans lasted 5:20-6:00 min long. Within a given scan, stimuli were of equal length, either $30,39,40$, or $45 \mathrm{sec}$ long. All told, 210 different visual stimuli were presented at least once; the most interesting stimuli were presented many times. Detailed descriptions of these stimuli are presented in the text and figure legends, with the associated results.

Image data were analyzed off line, using the following forms of analysis. (1) Movies were run of all (e.g., 180) images per slice, either as difference images or raw images. This furnished a dynamic yet tomographic view of the activity variations, as well as one index of head 


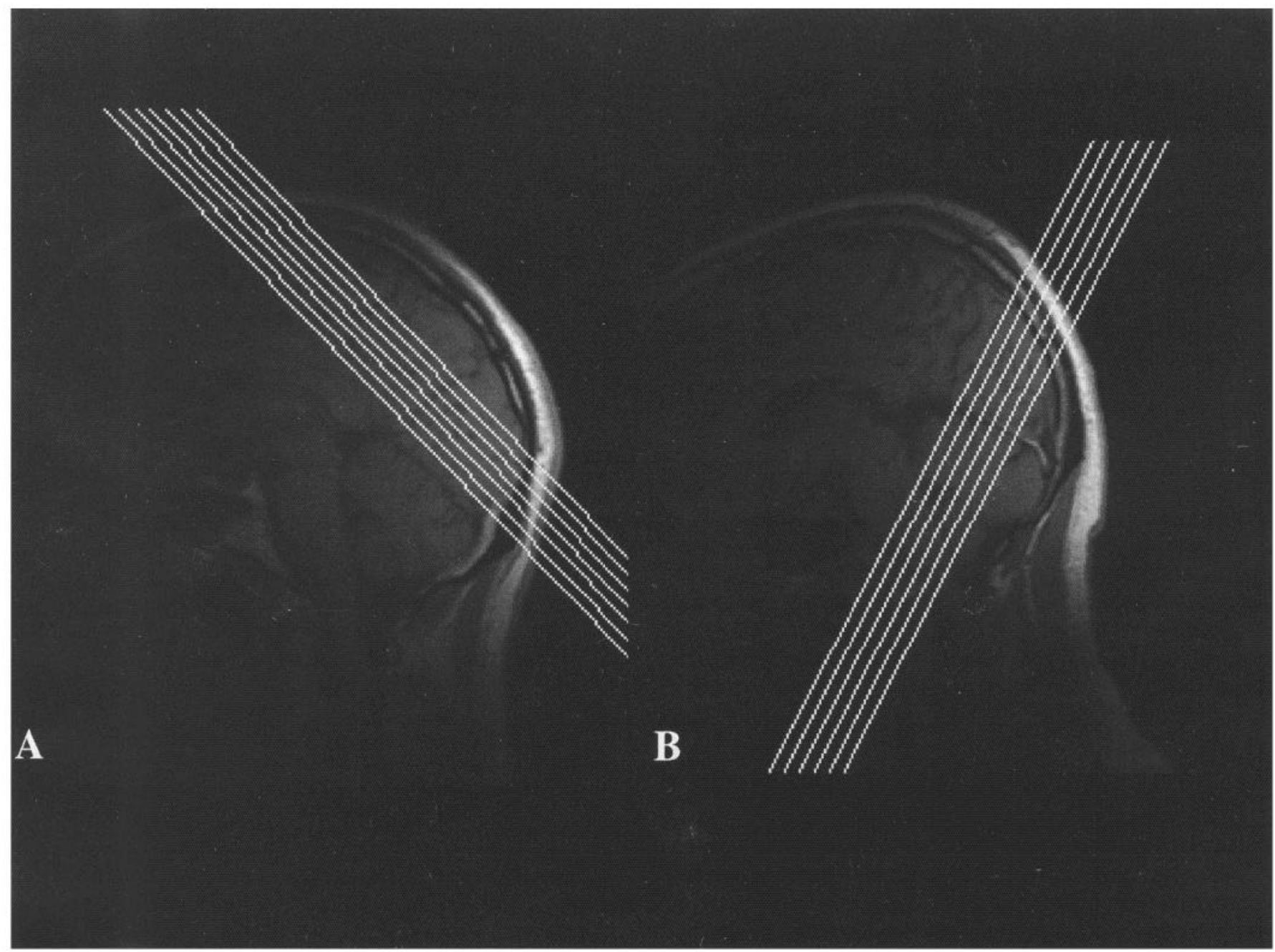

Figure 1. Typical scanning planes used in this study. Both panels show a midsagittal slice from a scout scan, with the slice planes used in the functional studies superimposed. Anterior is to the right, and posterior to the left. The slices in $A$ are oriented approximately parallel to the calcarine fissure, the slices in $B$ are approximately perpendicular to it. Slice thickness is $4 \mathrm{~mm}$ in $A$ and $6 \mathrm{~mm}$ in $B$.

motion. (2) Averaged difference images for each stimulus and control condition were displayed as gray-scale images. (3) Kolmogorov-Smirnov (Press et al., 1988; Stuart and Ord, 1991) analyses of stimuluslocked activity were computed and displayed in pseudocolor, scaled according to statistical significance, and superimposed on a gray scale high-resolution T1 image. (4) The time course of activation at each voxel or region of interest was displayed for the entire scan. The location of sampled regions was controlled on line by a mouse.

When image head motion was greater than 1-2 mm, and when it was not corrected by software reregistration algorithms (Woods et al., 1992; Jiang et al., 1994), the images were discarded. Time courses from the same volume of interest were often averaged in response to identical stimuli, to increase the signal/noise ratio and to minimize individual variations. Plots of time courses were not temporally smoothed.

Levels of activation were calculated by subtracting the averaged baseline MRI signal strength from the averaged activation, in response to each stimulus. Activation was expressed in percentage change relative to baseline, or in raw MRI signal levels. Data from the first 5-6 sec following stimulus onset or offset were deleted from quantitative analysis, consistent with the time course of fMRI dynamics. When baseline values dropped after stimulus offset ("undershoot"), amplitudes were measured relative to the corrected baseline level.

\section{Results}

\section{Intra-area retinotopic mapping}

To identify and distinguish retinotopic areas in our subjects, retinotopically restricted stimuli were presented within most scan- ning sessions. These included activation of upper-versus-lower, right-versus-left, and center-versus-peripheral visual fields.

Especially informative were stimuli activating the vertical versus horizontal meridia, since most retinotopic areas border each other along either vertical or horizontal meridian representations. In these tests, stimuli (flickering checkerboards and moving dots and gratings) were confined to pie-shaped wedges, centered on either the horizontal or vertical meridian. The wedges subtended $40^{\circ}$ per hemisphere $\left(40^{\circ}\right.$ along the horizontal meridian, or $80^{\circ}$ along the vertical meridian).

A typical result from these studies is shown in Figure 2, from a near-coronal slice (as shown in Fig. $1 B$ ). There are three representations of the horizontal meridian, paired in rough mirror symmetry across the two hemispheres (red in Fig. $2 A$ ). The one passing through the lateralmost depth of the calcarine fissure is the horizontal meridian representation of V1. The horizontal meridian superior to that (upper in Fig. $2 A$ ) is presumably that between dorsal V2 and the adjacent anterior area, presumptive V3. The most inferior (lowest) horizontal meridian representation marks the border between ventral V2 and VP, again extrapolating from the monkey literature.

The vertical meridia (shown in blue in Fig. $2 A$ ) are somewhat harder to distinguish, because they tend to lie on the medial 

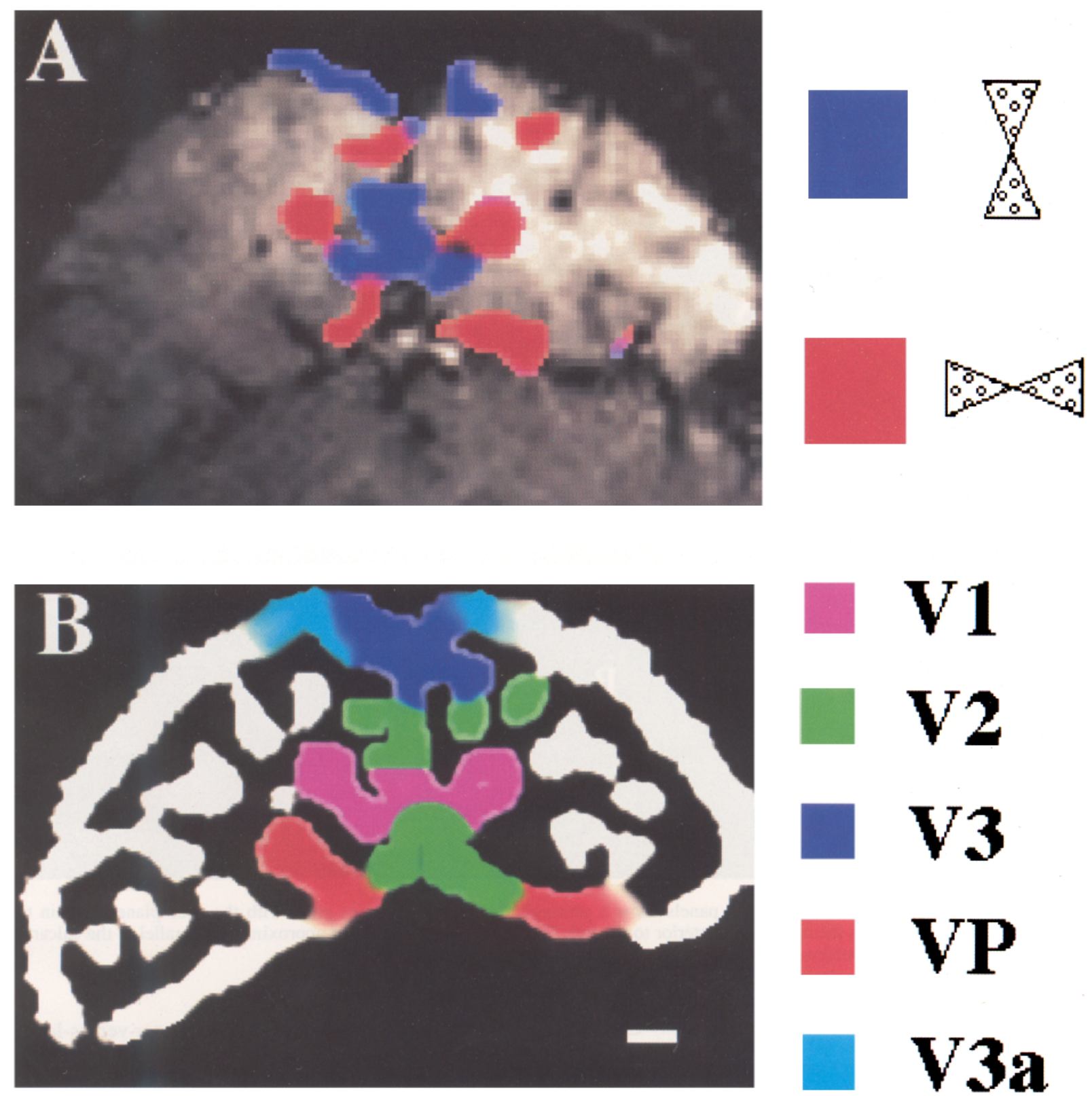

Figure 2. Functional labeling of the vertical versus horizontal meridian representations in one subject. The slice plane was perpendicular to the calcarine fissure, as shown in Figure $1 B$. Thus, superior-versus-inferior brain axes are approximately up-versus-down in this figure, and lateral is outermost. The stimuli were moving dot arrays, within paired pie-shaped wedges. The wedges were $40^{\circ}$ wide within each hemisphere (thus, $80^{\circ}$ wide on the vertical meridian). The dots within each pie-shaped wedge activated cells within retinotopically corresponding regions of the visual cortex. A shows the activation produced in a single slice. Activation was produced over wide regions of visual cortex; here, the pseudocolored regions indicate only regions activated specifically by stimuli centered on either vertical (blue) or horizontal (red) meridians. Presumptive human area V3 lies between the most superior vertical meridian representation (uppermost blue activation patches) and the horizontal meridian representation (red patches) just below that. Presumptive dorsal V2 lies between that horizontal meridian representation and the next lowest vertical meridian representation. Area V1 includes activated cortical regions in the calcarine fissure, extending through one horizontal meridian representation to the next lowest vertical meridian representation. Below that (extending to the lowest horizontal meridian representation) is ventral V2. Below that is presumptive area VP. These presumptive area boundaries are indicated on $B$. The approximate boundaries of the gray matter in $A$ were extracted by using a difference-of-gaussian filter with a center width of approximately $4 \mathrm{~mm}$. Where two adjoining areas, approximately equal in width, were activated by this stimulus, we estimated the area boundary to be midway through the activated patch. Where only one area was activated, the area boundary was placed closer to the outer edge of the activated region. Where area boundaries are undefined (e.g., the lateral borders of VP and V3A), this is indicated by diffuse color-white borders. The information about area boundaries in Figure $1 B$ was supplemented from other MRI scans, not shown here. The scale bar is $1 \mathrm{~cm}$.

bank. Nevertheless, areas near the vertical meridians dividing V1 and V2 can be seen on both ventral and dorsal medial banks. The most superior meridian in Figure $2 A$ is another vertical one, separating presumptive $\mathrm{V} 3$ from $\mathrm{V} 3 \mathrm{~A}$. In Figure $2 B$, this (and other, see below) retinotopic information is summarized to define area borders in this slice; similar information was available in most posterior slices.

Other retinotopically restricted stimuli activated upper-versus- 

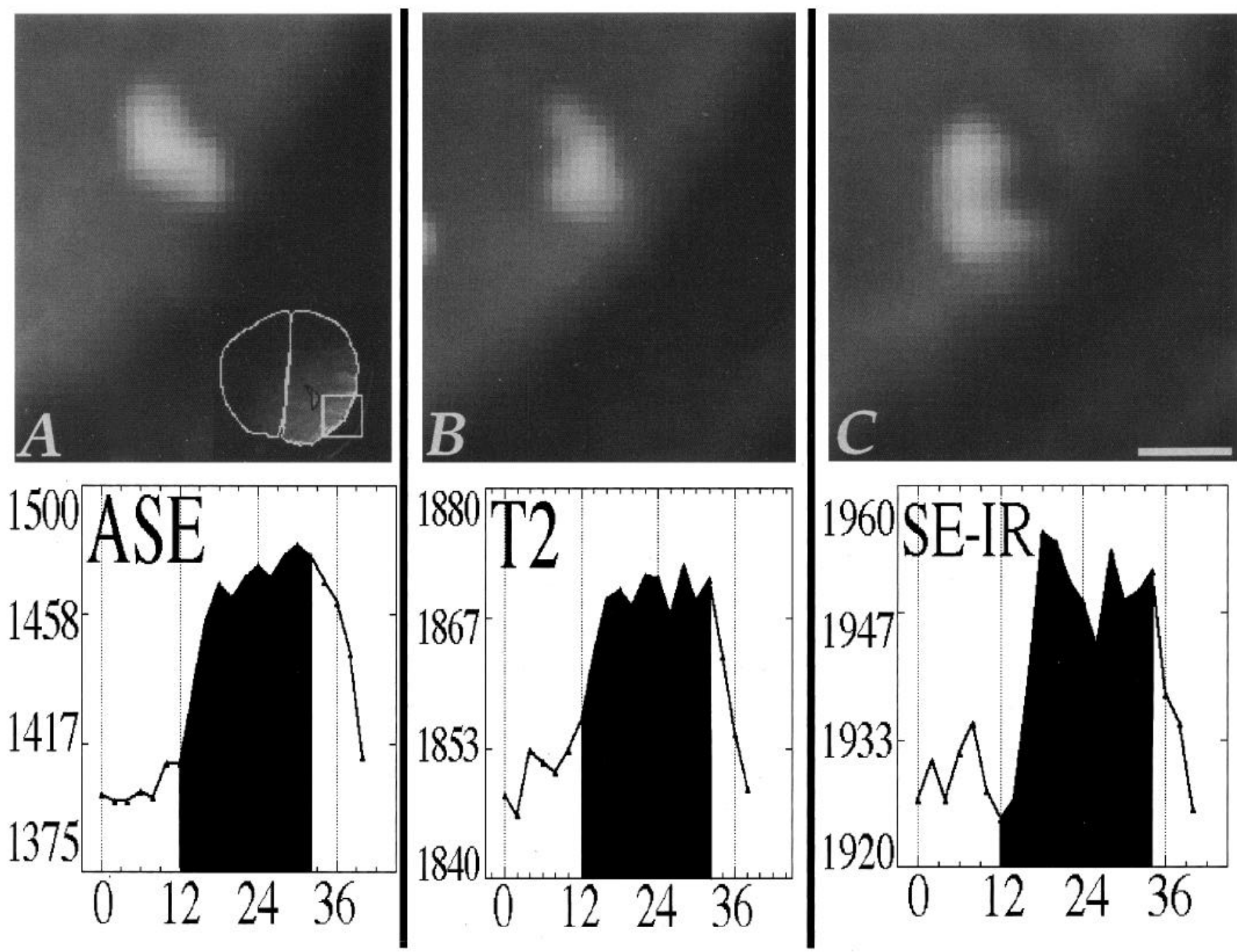

Figure 3. MRI activation in human area MT, produced by identical stimuli in three different scans. Information for each scan (all taken from the same subject, using approximately the same slice planes) is shown in both map form (upper rows) and in an activation time course (lower panels). $A$ shows the activation produced by radially moving random dots, in an asymmetric spin echo sequence $(T R=2000 \mathrm{msec}, T E=80 \mathrm{msec}$, delta $=-20$; Baker et al., 1993). $B$ was produced by the same stimuli using a T2-weighted sequence ( $T R=2000 \mathrm{msec}, T E=80 \mathrm{msec}$; Kwong et al., 1993). $C$ is similar, produced by a spin-echo inversion recovery sequence ( $T R=4000 \mathrm{msec}, T I=1100 \mathrm{msec}, T E=43 \mathrm{msec}$; Kwong et al., 1992 , 1993). $A-C$ are taken from the same slice. The inset in the bottom right of $A$ shows the location from which $A-C$ were taken. The "MT" activation in all three sequences occurs at approximately the same cortical location, although at widely different amplitudes. Gray scale levels in $A-C$ are normalized according to the level of peak activation in MT of each sequence. The minor topographic differences between activation sequences may reflect noise, head motion between scans (separated by up to $2 \mathrm{hr}$ ), or it may reflect actual differences in sources. Scale bar, $1 \mathrm{~cm}$. The lower panels show the response in MT, averaged over four presentations, produced by radially moving white dots on a black background. Time (in seconds) is indicated on the $\mathrm{x}$-axis (moving stimulus presented during period marked by gray), and MRI signal strength in the region of interest (MT) is indicated on the y-axis.

lower, central-versus-peripheral, and right-versus-left visual fields. Such results are described in detail elsewhere (e.g., Schneider et al., 1993). Such functional maps allowed us to distinguish between retinotopically specific cortical areas in each subject, for the same slice planes used in other functional tests. Other less retinotopic areas such as MT were distinguished by more global functional tests, such as selectivity for motion, contrast, color, etc. Areas were further defined based on cortical location and topography.

\section{MT maps based on different sequences}

It has been suggested that some MRI sequences may be less susceptible to vascular artifact than the gradient echo sequences typically used (Kwong et al., 1993; Turner et al., 1993). To test whether the results in this mapping study were highly sequence dependent, we stimulated with identical visual stimuli (radially moving random dots) while scanning MT in the same individual with (1) gradient echo (conventional or asymmetric spin echo, ASE), (2) spin echo inversion recovery (e.g., Kwong et al., 1992, 1993), and (3) T2-weighted (Kwong et al., 1993) sequences.

One example is shown in Figure 3. Paired activation maps (top row) and averaged time courses of activity (bottom row), taken from the same three scans, are shown for three different sequences. The activation amplitude produced by the ASE (Fig. $3 A$ ), the T2-weighted (Fig. $3 B$ ), and the spin echo IR (Fig. $3 C$ ) sequences varied greatly, as shown previously (Kwong et al., 1992, 1993; Bandettini et al., 1993). However, the localization 


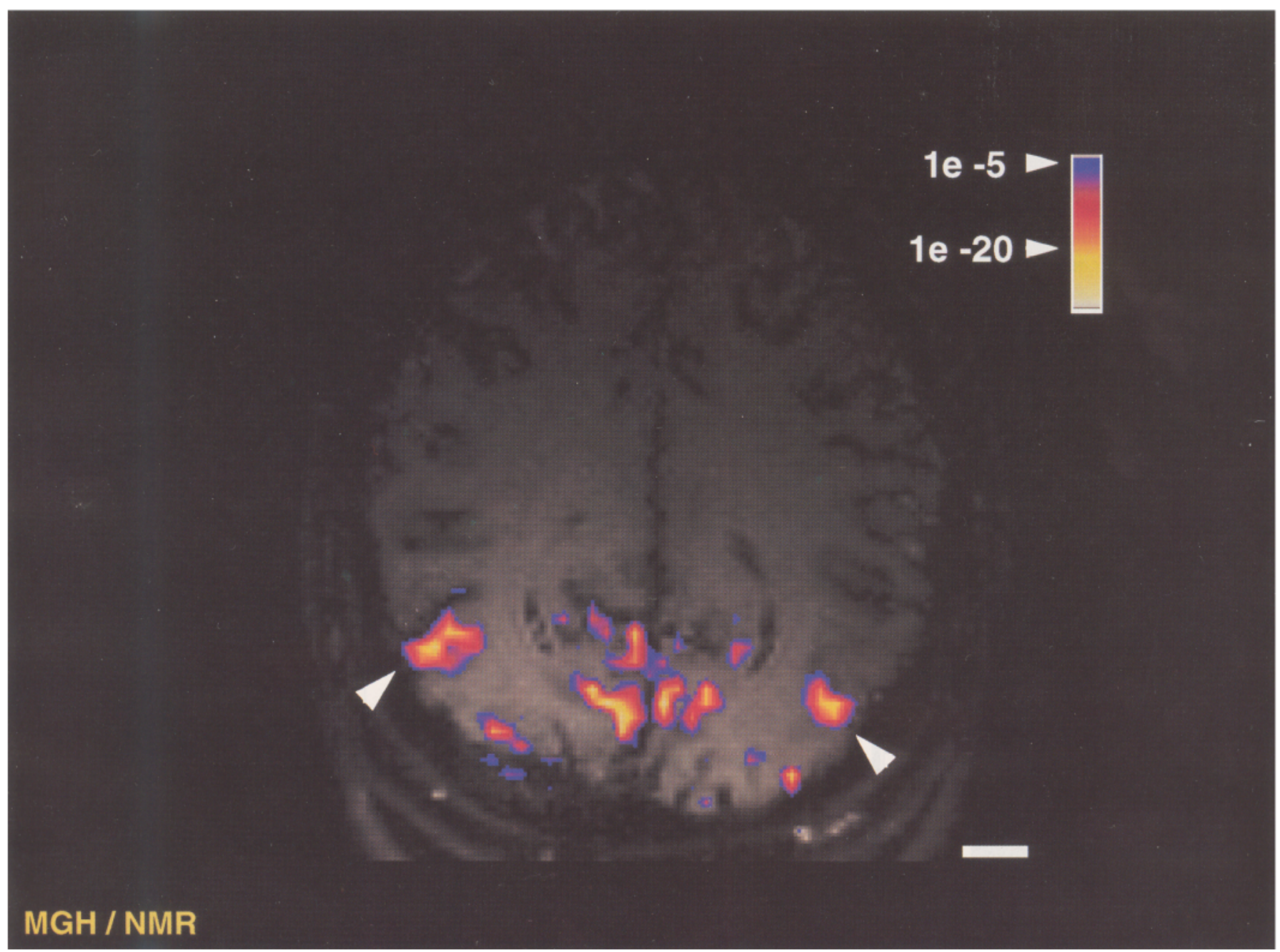

Figure 4. Lower-magnification view of bilateral activation in human area MT. The activation, indicated in pseudocolor, was produced by radially moving random dots, using an asymmetric spin echo sequence,. The scale bar on the right indicates the statistical significance of this activation; in this example it ranges up to a random probability of less than $10^{-20}$ in MT. In this slice (parallel to the calcarine fissure, but two slices inferior to it) activated regions near the midline are mostly ventral V2, which has some motion bias (see Fig. $9 A$ ). The achromatic image in the background is a T1-weighted image from the same slice, to clarify the anatomy. Following radiologic conventions, the left hemisphere appears on the right of this figure, and vice versa. The surface coil was placed on the right posterior pole, which leads to a nonuniform sensitivity to MRI signals, most visible from lower to upper in this figure. Scale bar, $2 \mathrm{~cm}$.

of area MT did not vary greatly. The small differences in apparent localization between Figure $3 A-C$ may be artifactual, due to noise (e.g., Fig. $3 B$ ) or head movement (the scans were taken up to $2 \mathrm{hr}$ apart), or the differences may reflect sequence-dependent differences in signal source. No differences in stimulus selectivity (see below) were noted. We conclude that results described below are not greatly dependent on the exact MRI sequence used, except in terms of signal amplitude and signal/ noise ratios.

\section{Motion selectivity}

Our standard test for areas sensitive to visual motion was to compare the ratio of activation produced by moving stimuli to that produced by stationary stimuli, otherwise identical. The stimulus used most often was a random dot array (white dots on black background; $2 \%$ density), presented while (1) expanding, (2) contracting, and (3) stationary. Radially moving dots were used partly because when fixated, they do not induce nystagmus, unlike dots moving in a single direction. Moving and stationary stimuli were presented for $40 \mathrm{sec}$ at a time, separated by $40 \mathrm{sec}$ periods of spatially uniform stimulation.

High-contrast, moving stimuli produced activation in many different areas of visual cortex, in most subjects. In one distinctive lateral area, responses to fixated stationary stimuli were absent or markedly attenuated; the area is thus motion selective (see Figs. 4, 5B). We refer to that lateral area of high motion selectivity as MT. Typically, the high motion selectivity in MT contrasted sharply with responses in other areas including V1 (see Fig. 5A) and V3 (see below): in the latter areas fMRI amplitudes produced by stationary stimuli were more similar to those produced by corresponding moving stimuli.

The Talairach coordinates of MT in our studies (lat 45, post 76 , sup $3 ; \mathrm{SD}=3.6,7.5$, and $2.5, n=6$, respectively) are in good agreement with those of a motion-specific area ("V5") described in earlier PET studies (lat 42, post 69, sup/inf 0, SD 8.4) (Watson et al., 1993). Although Talairach coordinates of area MT are not available from histological studies (Clarke and Miklossy, 1990; Sereno and Allman, 1991; Tootell and Taylor, 

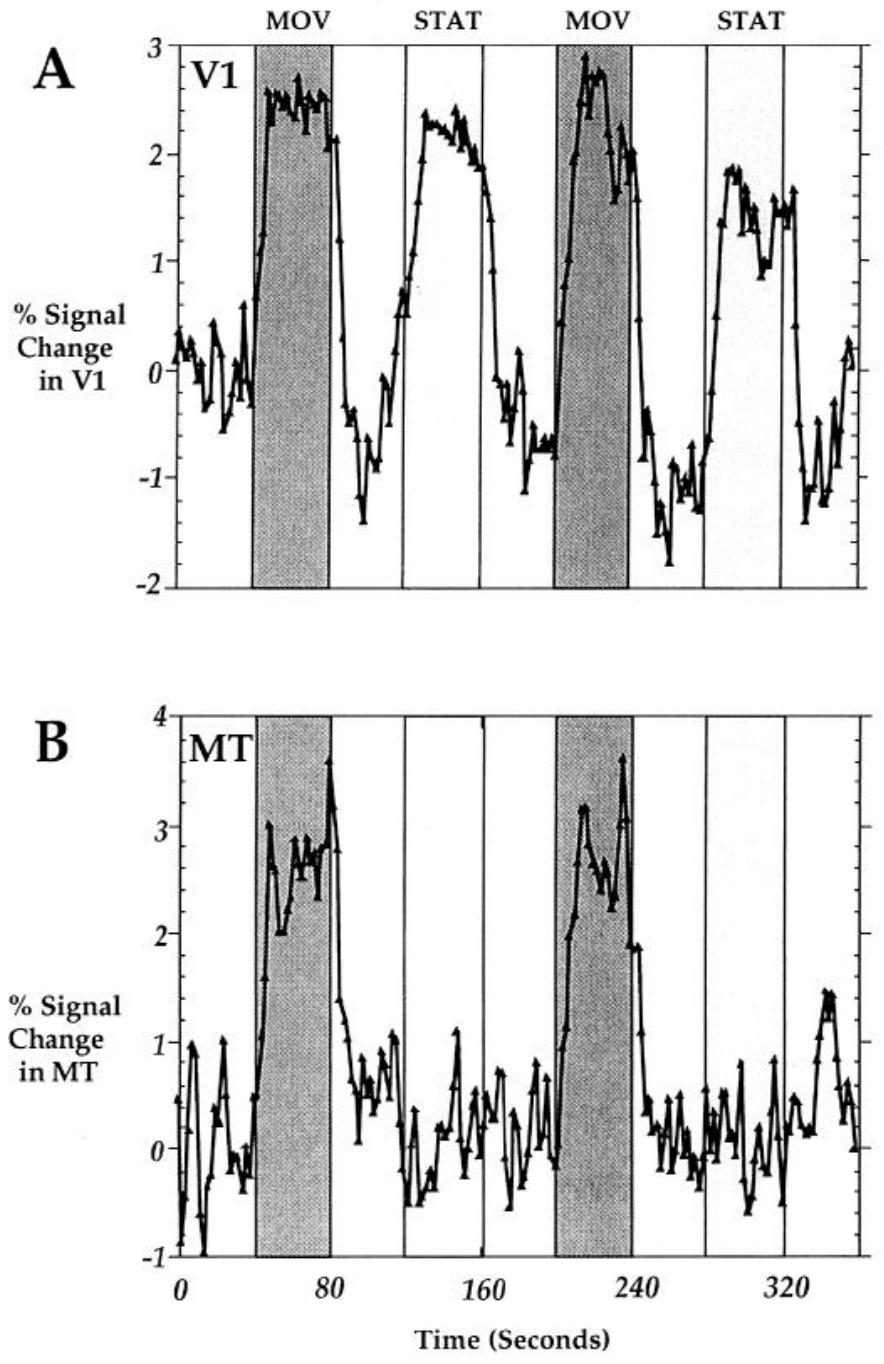

Figure 5. Quantitative data showing that area MT responds selectively to moving (relative to stationary) stimuli. Area V1 is much less selective. The graph shows the time course of MRI signal amplitude during a $6 \mathrm{~min}$ scan, sampled every $2 \mathrm{sec}$ in each slice. Time courses are displayed from V1 $(A)$ and MT $(B)$, from the same subject, in response to the same stimuli during the same time periods. Each trace is the average of two serial stimulus presentations. During each scan, the random dots moved radially (either expanding or contracting during each period) during two $40 \mathrm{sec}$ periods, and they were stationary in two periods of the same duration. These periods were separated by $40 \mathrm{sec}$ periods of baseline stimulation without random dots. Moving and stationary periods are indicated above the graph. The data from MT are noisier than that from VI because more voxels could be sampled from VI, since it is a larger area. The amplitude increased approximately $3 \%$ within both areas in response to the moving (expanding or contracting) random dots. Stationary random dot arrays, otherwise identical, produced very robust responses in V1 but little response in MT. This is consistent with earlier evidence that area MT is motion selective. The roughly equivalent response in MT to expanding versus contracting stimuli suggests an absence of bias in the number of cells preferring expanding versus contracting motion in human MT. Prominent, localized decreases in MRI amplitude ("undershoots") occur in V1 following stimulation offset, here lasting approximately $40 \mathrm{sec}$. Such undershoots were less obvious in this and other data from MT. The absolute amplitudes of activation in area MT were often smaller than those in V1, perhaps reflecting partial volume sampling from a small area.

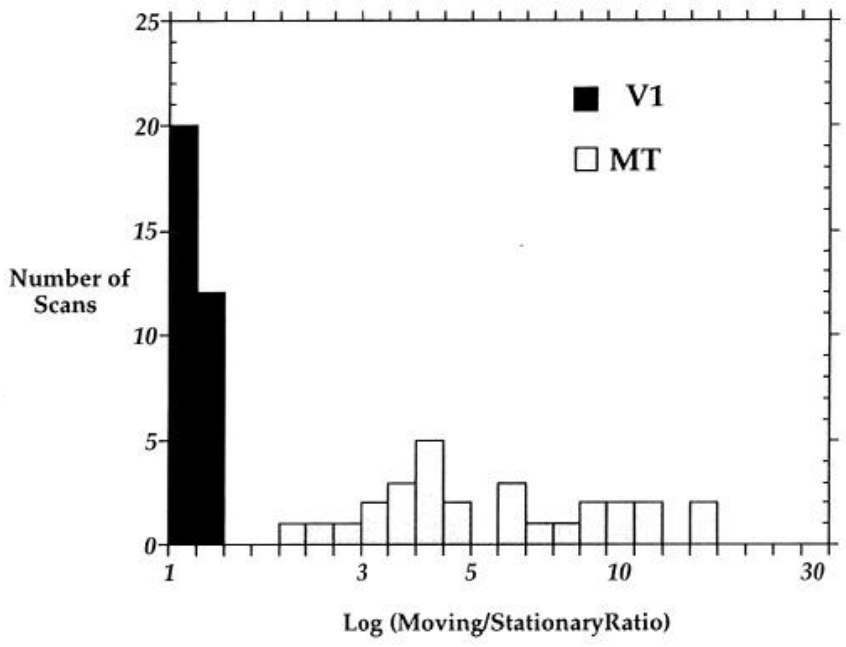

Figure 6. Variability in motion selectivity across scans. For each individual scan in which the radial motion-versus-stationary random dot stimuli were presented (e.g., Fig. 4), the percentage change in activity (moving/stationary) was sampled in MT and V1. Data were obtained from 32 scans in 13 subjects for V1, and 29 scans in 12 subjects (a subset of the V1 sample) for MT. In area VI, values were tightly clustered (range $=1.0-1.3$ ). Values in MT were always more motion-selective than those in V1, but they were more variable (range $=2.0$ 16.1). The increased variability may reflect inadvertent partial volume sampling with adjacent areas of lesser motion selectivity, and/or the effects of slight changes in the numerator on the motion selectivity ratio.

1994), the location of distinctive histological features also matches the location of the PET and fMRI motion-specific MT, insofar as the different measures can be compared.

We could discern no consistent relationship between the location of MT relative to surrounding cortical gyri. However, the gyri themselves are not very consistent here. MT is usually (but not always) buried within a shallow sulcus, as described in Watson et al. (1993). However, this could be simply because more of the surface area in this region is gyral rather than sulcal.

In the macaque, it has been reported that cells preferring outward-radiating directions of motion outnumber cells preferring inward-radiating motion, by a factor of approximately $2-3$, in MT (Albright, 1989) and MST (Tanaka and Saito, 1989, Graziano et al., 1993; see also Lagae et al., 1994). To test for an analogous direction bias in man, we compared fMRI amplitudes in response to expanding versus contracting dot fields. No significant differences were found (respectively, means $=3.38$ and $3.52 \%$ activation, $\mathrm{SDs}=0.34$ and 0.5 , SEs $=0.11$ and 0.17 ).

To assess intersession variability, we plotted the motion selectivity ratios from areas V1 versus MT, for all available scans (see Fig. 6). The moving/stationary ratios in V1 are quite consistent, ranging from 1 to 1.3. Analogous ratios in MT range more widely, from 2.2 to 16.1 . Thus, MT is consistently more motion selective than V1, although the motion selectivity in MT is more variable.

The increased variability may be partly due to inadvertent partial volume sampling of activity in areas immediately ventral to MT (perhaps MST or FST); these areas typically have a motion selectivity ratio near 2 , when they can be functionally distinguished by other tests (motion coherence, retinotopy, and eye movements), described elsewhere.

The generality that MT is motion selective needs to be qualified. Flickering stationary stimuli also produced fairly vigorous activation in MT (see Fig. 7), as well as in other visual cortical 


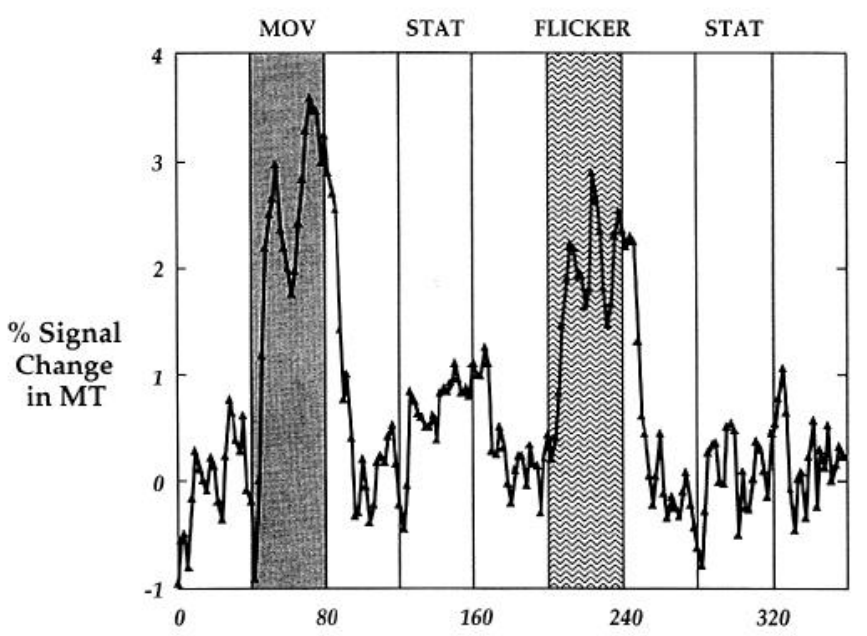

Time (Seconds)

Figure 7. Activation of area MT by flickering stationary stimuli. This experiment was similar to that illustrated in Figure 5. However, the third stimulus was a stationary random dot array, flickering at $2-3 \mathrm{~Hz}$. It produced almost as much activation as the moving random dot array (first stimulus), and significantly more than the nonflickering stationary stimuli (second and fourth stimuli). The time course is the average of all five identical stimulus presentations, from two subjects. The strong response to flickering stationary stimuli indicates that area MT is not always "motion-specific."

areas. Though this is inconsistent with a detector that is strictly motion-sensitive, it is consistent with the behavior of area MT neurons in nonhuman primates. Optical recording of intrinsic signals (which also reflect activity-driven cortical changes in blood oxygenation and flow) show that owl monkey MT can be activated by stationary flickering as well as by moving stimuli (Malonek et al., 1994). Single units in macaque MT can also be activated by stationary, flashed stimuli (e.g., Zeki, 1980; Albright, 1984; Felleman and Kaas, 1984; Rodman and Albright, 1989; Lagae et al., 1994).

The motion specificity in MT and other areas remained similar, when tested by a wide range of other moving stimuli. These stimuli included (1) gratings (square, rectangular, or sine wave, at one or systematically varied orientations and spatial frequencies), and (2) dot arrays (random or regular arrays, white dots on a black background, density $0.5-50 \%$ ). All these stimuli moved coherently in a single plane. Using the timing, resolution, and analysis described here, we could not discriminate between activity produced by one direction versus the opposing direction (presented at different times, to probe for direction columns), nor between random dot arrays moving coherently in a single direction versus moving in opposing directions concurrently and transparently (a probe for band/interband segregation in MT; Born and Tootell, 1992).

\section{Motion selectivity in other cortical areas}

Other areas (determined as described in Fig. 2 and above) also showed some motion selectivity, as revealed by our standard moving-versus-stationary test. The activation in such areas was often lower in amplitude and/or selectivity than that in MT.

Many subjects showed relatively high motion selectivity immediately surrounding striate cortex, in area V2 (see Fig. 8A). We have not yet resolved whether motion selectivity varies within V2, for example, within different stripe subdivisions. There
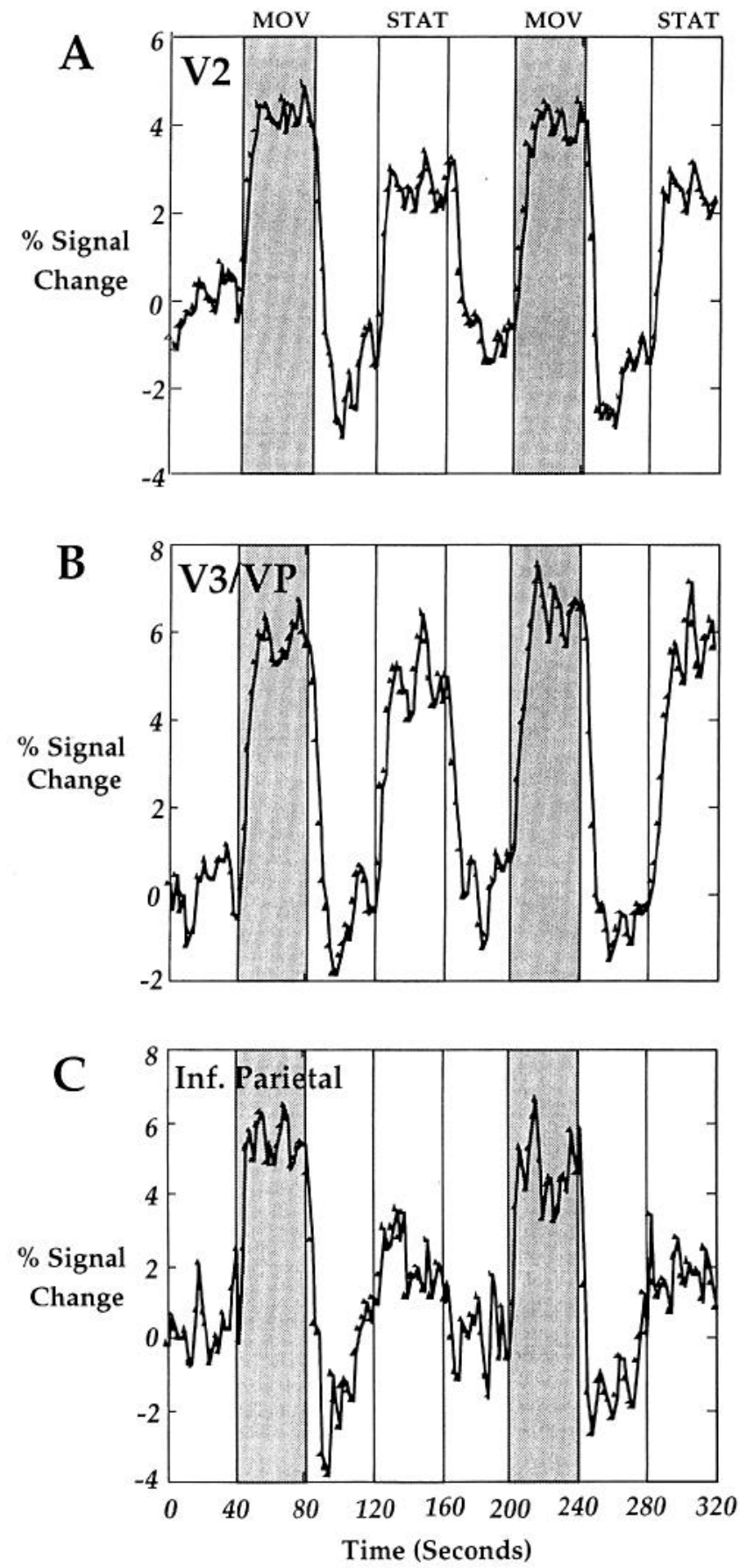

Figure 8. Time course of responses to radially moving versus stationary random dot stimuli in human visual areas V2 $(A), \mathrm{V} 3(B)$, and in selected regions of inferior parietal cortex $(C)$. The time courses are averages of two identical stimulus presentations from two representative subjects. The limits of area V2 and V3 were determined from the activity patterns produced by stimuli centered on the vertical-versus-horizontal meridia, as shown in Figure 2, and other retinotopically specific stimuli. Activity in area V2 is slightly more motion biased than that in V1, but V3 shows very little motion bias. Activity in inferior parietal cortex is shown only for selected subregions that are motion specific: other areas of inferior parietal cortex are not motion biased.

was little motion selectivity in retinotopically determined area V3 (see Fig. 8B).

Distinct portions of inferior parietal cortex (within $3 \mathrm{~cm}$ of the medial-lateral border, just posterior to the intraparietal sul- 
cus) showed motion selectivity (see Fig. 8C). This is consistent with tract tracing experiments in monkeys (Andersen et al., 1990; Bousaoud et al., 1990) showing that major tributaries of the dorsal stream project to inferior parietal cortex. Furthermore, motion selectivity has been shown in some single units there (e.g., Hyvarinen, 1981; Motter and Mountcastle, 1981; Andersen et al., 1987).

\section{Contrast sensitivity in VI and MT}

One striking feature of macaque MT is that it receives prominent input from cells in the magnocellular stream (Lund et al., 1976; Maunsell and Van Essen, 1983a; DeYoe and Van Essen, 1985; Shipp and Zeki, 1985). In the LGN, magnocellular neurons have markedly higher contrast sensitivity than their counterparts in the parvocellular layers (Shapley et al., 1981; Kaplan and Shapley, 1982; Derrington and Lennie, 1984; Shapley and Perry, 1986; Purpura et al., 1988; Sclar et al., 1990). Average single unit contrast sensitivity increases even further in area MT neurons (Sclar et al., 1990). In single units in prior area V1, the average contrast sensitivity is much lower than that in MT. If this magno-/parvocellular distinction also holds true in human cortex, we should expect to find a high contrast sensitivity in the fMRI response of human area MT, relative to that in V1.

To make such measurements, we presented a moving (continuous unidirectional horizontal motion at $12 \% \mathrm{sec}$.) vertical square wave grating $(0.1 \mathrm{cycle} /$ degree $)$, at systematically varied contrasts. In preliminary tests, stimuli of differing contrast were ordered randomly. In subsequent tests, they were presented in order of increasing contrast, to minimize the possibility of contrast adaptation. Grating stimuli were temporally separated by stimuli of zero contrast but equal mean luminance.

In area V1, such stimuli produced a progressive increase in MRI amplitude with increasing log contrast, across most of the contrast range tested (see Figs. 9, 10). However, in MT, reliable responses could be obtained through the lowest contrasts tested $(1.6 \%)$, and were apparently saturated at contrasts higher than that (see Figs. 9, 10). As in all other comparisons between MT and $\mathrm{V} 1$, the contrast response differences were obtained from the same subjects, at the same times, using the same stimuli. Figure $10 B$ shows that similar results were obtained when contrast sensitivity results from all contrast gain tests were pooled. Similar contrast differences were seen between V1 and MT when contrast-varying concentric rings were used as test stimuli; this controls for the possibility that OKN (produced by the vertical grating) contributed to the contrast effect. The differences in contrast sensitivity between these two areas suggests that (1) human area MT receives a dominant input from a magnocellular stream, and (2) this magnocellular stream is functionally specialized, as in macaque (Sclar et al., 1990).

\section{Contrast sensitivity in other cortical areas}

The robust differences in contrast sensitivity between V1 and MT encouraged us to use stimulus contrast as a probe to look for magnocellular stream dominance in additional cortical areas, also visible in the same scans.

The contrast sensitivity in human V2 was only slightly higher than that in V1, whereas the contrast sensitivity in V3 was indistinguishable from that in MT (see Fig. 10A). The high contrast sensitivity in human V3 is consistent with related evidence in macaque: V3 is the only cortical area besides MT that receives major input from magnocellular-dominated striate layer 4B (Burkhalter et al., 1986), and cells in macaque layer 4B have
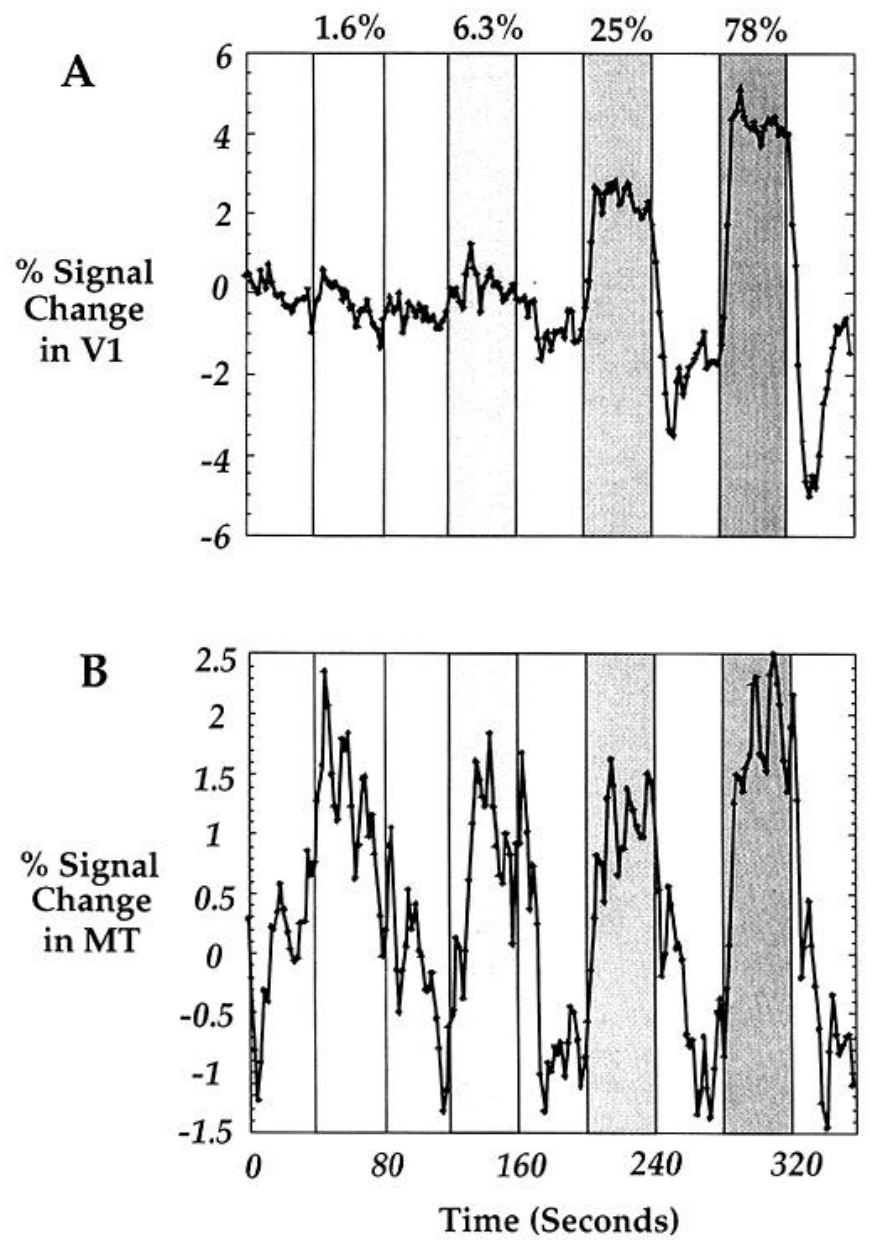

Figure 9. Representative time courses in response to gratings of different luminance contrast, in V1 $(A)$ and MT $(B)$. Stimuli were moving $(12 \% \mathrm{sec})$, vertical square wave gratings (spatial frequency $=0.1 \mathrm{cycle} /$ degree). Periods of zero contrast and equal mean luminance were interspersed between periods of contrast 1.6, 6.3, 25, and 78\% (indicated above graph). The time courses illustrated are an average of two stimulus presentations from one subject. Gratings of intervening contrast $(3.1,12.6,51$, and $82 \%)$ were presented in other scans during the same scan session. In V1 $(A)$, MRI amplitudes increased steadily with increasing contrast. In MT $(B)$, MRI amplitudes were of approximately equal amplitude (saturated) at all higher contrasts. As elsewhere, time course data from MT appears noisier because it is a smaller cortical area than V1; thus, samples were taken from a smaller number of voxels. These differences in fMRI contrast sensitivity are consistent with those seen earlier in single unit studies of contrast gain in V1 and MT (Sclar et al., 1990), and they are consistent with a magnocellular-stream bias in human MT.

a relatively high contrast sensitivity (Hawken and Parker, 1984; Hawken et al., 1988; Tootell et al., 1988b; Hubel and Livingstone, 1990). The striate-like contrast sensitivity in human V2 also makes sense: macaque $\mathrm{V} 2$ receives most of its input from striate layers $2+3$, which have a lower contrast sensitivity (Tootell et al., 1988b; Hubel and Livingstone, 1990) and are more dominated by parvocellular stream inputs (Lund and Boothe, 1975; Fitzpatrick et al., 1985; Yoshioka et al., 1993).

The contrast sensitivity in activated areas of inferior parietal cortex was similar to that in V3 and MT. This strongly suggests a prominent magnocellular stream input into human inferior parietal cortex, as one might expect from the organization of macaque visual pathways. 

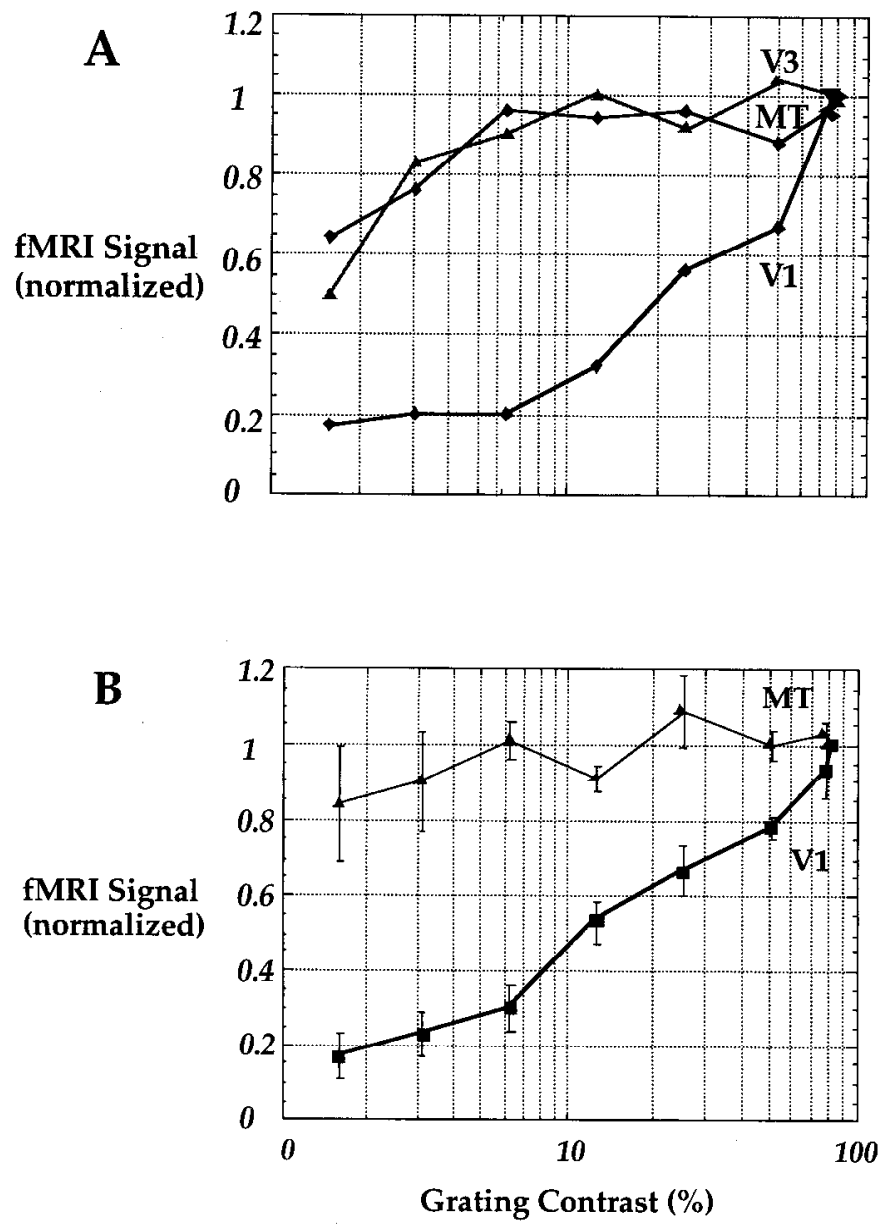

Figure 10. Luminance contrast gain functions derived from MRI measurements. $A$ shows averaged data from two complete contrast gain functions in a single subject, from areas MT, V1, and V3. The amplitudes in each area were normalized relative to the amplitude produced by the highest contrast presented $(82 \%) . B$ shows averaged data from all subjects tested with these contrasts, amounting to eight complete stimulus presentations in four subjects. SE bars are indicated for each data point. The amplitudes from each area are nommalized as in $A$, since absolute levels of activation are not meaningful in this context. In both $A$ and $B$, the contrast sensitivity in area MT is much higher than that in VI, over most of the contrast range. 'The half-amplitude of the contrast gain function in $\mathrm{MT}$ is near 1\%, varying slightly in different subjects. At most contrasts above that, MRI amplitudes in MT are saturated. In $\mathrm{V} 1$, one needs approximately $15 \%$ luminance contrast to produce a half-amplitude response, and the response continues to increase up to the highest contrast tested. The high contrast sensitivity in human MT strongly suggest that it receives dominant input from magnocellular stream inputs, as in macaque MT.

\section{Equiluminant color}

In humans, it has been shown that the visual motion in colorvarying stimuli appears to slow down (or even stop) when the luminance of the colored sectors is equated ("iso- or equiluminance") (Ramachandran and Gregory, 1978; Anstis, 1970; Cavanagh et al., 1985; Gorea and Papathomas, 1989; Cavanagh and Anstis, 1991; Cavanagh, 1993). This has been attributed to reductions in the activity of area MT neurons at equiluminance (e.g., Livingstone and Hubel, 1988). In single unit tests of macaque monkey, area MT neurons typically decrease firing rates at or near equiluminance, but do not become silent (Charles and Logothetis, 1989; Saito et al., 1989; Albright, 1991; Gegenfurtner et al., 1994).
To study this issue, we presented vertical gratings (sinusoidal or square wave), varying in luminance or color or both. In the test mode (see below), a red-green stimulus moved coherently in a single direction and speed.

In the equiluminance calibration mode, the stimulus was as follows. First, a red-black and a green-black counterphasing grating were added, $180^{\circ}$ out of phase. Both counterphased gratings were in turn composed of two smoothly moving sinusoidal gratings, moving in opposing directions. A small amount of luminance contrast (e.g., 10\%) was added to one of the two moving gratings for each color-black combination, so that the red black grating had an apparent movement to the right, and the green-black had an apparent movement to the left. The subject's task was to adjust the intensities of the red-black and greenblack gratings by using a mouse until the overall apparent motion was nulled or balanced. Approximately 10 measurements were made and averaged for each subject. The equiluminance measurements were made outside the magnet immediately prior to the scanning session, using the same software and optics as were used during the actual experiments.

The test stimulus, presented inside the magnet, was a continuously drifting square wave grating. The mean luminance was approximately $200 \mathrm{Ft} . \mathrm{L}$., and the dominant wavelengths of the red and green were roughly 610 and $540 \mathrm{~nm}$, respectively. The grating was defocused slightly $(\sim 0.5 \mathrm{D})$ to minimize any luminance artifacts at the red-green borders. The spatial and temporal frequencies of the grating were low (spatial frequency = $0.1 \mathrm{cycle} /$ degree; temporal frequency $=0.8-1.0 \mathrm{~Hz}$ ), to maximize the difference between luminance and color channels at equiluminance (e.g., Hawken et al., 1994). The grating was either (1) black-white ( $\sim 85 \%$ contrast), (2) color-black (red-black or green-black, $\sim 85 \%$ contrast), or (3) red-green, at the individual's equiluminance setting and at systematically varied settings bracketing equiluminance.

Figure 11 shows the average responses from all our colorluminance tests in MT and V1. The red-green ratios have been converted to equivalent units of luminance contrast, so that green-black (85\% luminance contrast) appears at the left, and red-black ( $82 \%$ luminance contrast) appears to the right. Response amplitudes from different subjects are normalized to each other, based on their response to black-white gratings (amplitude $=1$ ). In MT, responses at equiluminance ( $0 \%$ contrast) decreased to approximately three-fifths of that produced by blackwhite stimuli. Responses to stimuli varying maximally in both color and luminance (red-black, green-black) were similar to those produced by luminance variations alone. The width of the equiluminance dip is fairly broad (full width at half-minimum $=\sim 35 \%$ luminance contrast). Responses in area $\mathrm{VI}$ during the same scans showed no significant decrease at equiluminance.

\section{Interhemispheric retinotopy}

In macaque striate cortex, receptive fields are small and confined to the contralateral visual field (e.g., Daniel and Whitteridge, 1961; Hubel and Wiesel, 1969; Tootell et al., 1988a). In highertier areas, receptive fields become progressively larger, and they extend further into the ipsilateral visual field. Macaque MT occupies an intermediate position in this hierarchy: its receptive fields are approximately 5-10 times the size of those in V1 and extend up to $20^{\circ}$ into the ipsilateral visual field (Gattass and Gross, 1981; Van Essen et al., 1981; Desimone and Ungerleider, 1986; Maunsell and Van Essen, 1987; Albright and Desimone, 1987). Areas surrounding MT (e.g., MST, FST, V4, area 7) have 


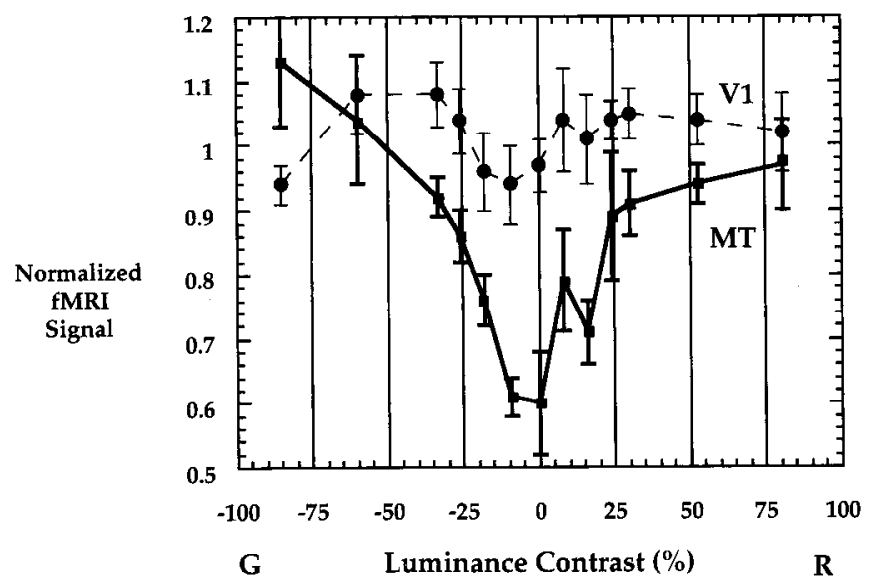

Figure 11. Response of human areas MT and V1 to color-varying gratings at equal and systematically unequal luminances. For each data point, the $y$-axis shows the amplitude of the MRI response to a moving red-green grating (spatial frequency $=\sim 0.1$ cycle/degree; temporal frequency $=0.8-1 \mathrm{~Hz}$ ). These values are expressed in percentage change, relative to baseline conditions lacking a grating. In both V1 and MT, all responses are normalized (amplitude $=1.0$ ) to the response to an achromatic (black-whitc) grating of identical spatial and temporal parameters and high $(\sim 85 \%)$ contrast, sampled during the same scans. On the $\mathrm{x}$-axis are luminances of the red-green grating, expressed in terms of percentage luminance contrast for each subject. Maximum green bias ( $G=$ green/black) appears on the left, and maximum red bias $(R=$ red/black) appears on the right. The fMRI response to each subject's equiluminance point is shown at zero luminance contrast (grating = red/green). The graph pools all data gathered using these parameters, from three subjects and 4-16 stimulus presentations (12 difference images per presentation) per data point. Error bars are indicated for each data point. In MT, responses over the extremes of the color-luminance range are within $10-20 \%$ of each other, centered around 1.0 , the amplitude produced by the black-white grating. At equiluminance, responses decrease to approximately $60 \%$ of that value. The full bandwidth of this dip at half-minima is approximately $35 \%( \pm 17 \%)$ luminance contrast. In V1, the response function is much more flat, showing only a very mild equiluminance dip.

even larger receptive fields, including more representation of both the contralateral and ipsilateral visual fields.

To test whether the interhemispheric retinotopy in human MT is similar to that in monkey, we presented (in 40 sec alternation) moving regular dot arrays confined to either the left or right hemifield, extending all the way to the vertical meridian. In fMRI studies of area V1, such stimuli have been shown to specifically activate the stimulated hemisphere (Belliveau et al., 1992; Kwong et al., 1992). However, when similar stimuli were used in the present study, human MT was activated in both left and right hemispheres (ratio of activation in ipsi- versus contralateral hemispheres $=\sim 0.9$; see Fig. 12B).

In MT, we obtained significant hemifield alternation only when we removed ("trimmed") the dot fields from the vertical meridian and some angular extent (e.g., $20^{\circ}$ ) on either side of it. In addition, the fixation spot was displaced away from the center of the trimmed stimuli $\left(2^{\circ}\right.$ for the $140^{\circ}$ stimulus, $4^{\circ}$ for the $100^{\circ}$ stimulus), to compensate for fixation instability and interhemispheric activation around the foveal representation. Such trimmed stimuli produced activation that was much more specific to the stimulated hemisphere than the original $180^{\circ}$ hemifield stimulus (see Fig. 12B).

Combined results from these experiments suggest that receptive fields in human MT extend more than $20^{\circ}$ into the ipsilateral visual field. Areas adjacent to human MT were more equally

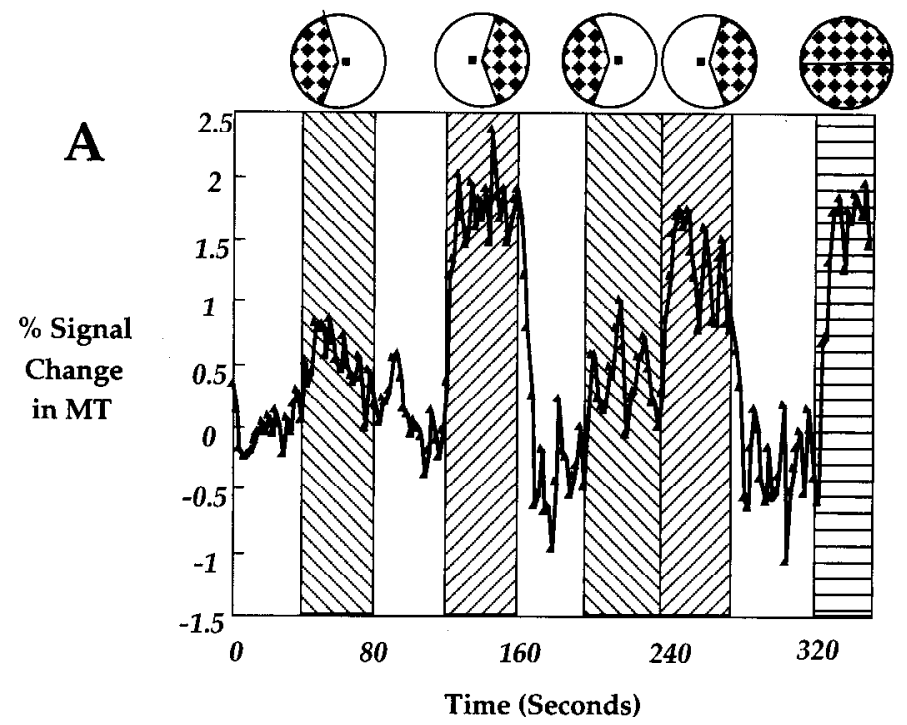

B

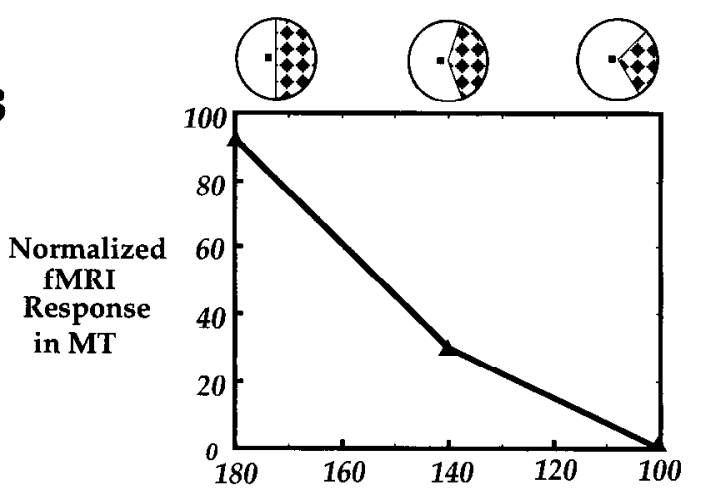

Stimulated Ipsilateral Visual Field (Deg)

Figure 12. Measurement of the extent of interhemispheric overlap in human area MT in the left hemisphere. $A$ shows the time course of activation produced by stimulation with a moving rectangular dot array. In the "ipsi" and "contra" conditions, the dot array was confined to cithcr ipsilateral or contralatcral visual ficlds. In this experiment it was furthermore deleted from $20^{\circ}$ of the visual field abutting the vertical meridian, and the fixation point was additionally moved approximately $2^{\circ}$ into the blank visual field. The stimuli used in each time period are diagrammed schematically above the graph. Periods of ipsilateral visual field stimulation are indicated by lines sloping downward from left-toright, and contralateral stimulation is indicated in time periods with the line orientation reversed. The final period of full-field stimulation is indicated with horizontal lines. The time course is an average of two stimulus presentations from a single subject. Using this stimulus, activation in the ipsilateral visual field produced approximately $30 \%$ of the amplitude produced by activation of the contralateral visual field $(A$ and middle data point in $B$ ). Stimulation by dot arrays extending all the way up to the vertical meridian (leftmost, $180^{\circ}$ condition in $B$ ) produced ipsilatcral activation that was almost cqual to that produced by contralateral activation, and dot arrays sparing even more of visual field adjacent to the vertical meridian produced essentially no activation when appearing in the ipsilateral visual field (rightmost, $140^{\circ}$ condition in $B$ ).

activated by both left and right hemifield stimuli, even when visual field regions along the vertical meridian were spared. These results are generally consistent with the extent of interhemispheric activation in macaque MT. However, more precise estimates were difficult duc to incomplete fixation during the unilateral stimulation, because the interhemispheric activation 


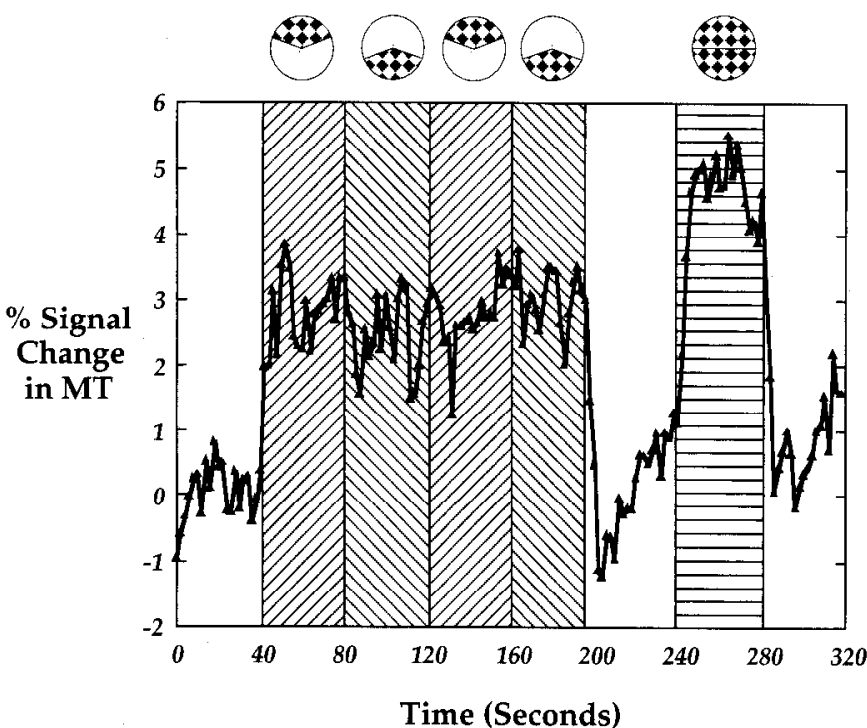

Figure 13. Response of human MT to stimulation in upper versus lower visual fields. Activation was sampled from all of the area. The time course is the average of nine stimulus presentations from two subjects. Stimuli were moving, low-density, planar-motion rectangular arrays of white dots on a black background. In the first four stimulus periods, the dots were confined to either upper or lower visual fields, in alternation. During the last stimulus period, they extended throughout the whole visual field. The stimuli are diagrammed schematically above their corresponding time periods above the graph. Responses to upperversus-lower visual field were indistinguishable from each other in amplitude, and responses to the whole-field stimulation were significantly greater than that to either subfield alone. This evidence argues against a large bias in the representation of upper-versus-lower visual fields in human MT.

falls off nonlinearly with distance, and because comparable fMRI measurements have not been made in macaque.

\section{Superior versus inferior retinotopy}

In macaque $\mathrm{MT}$, single unit data suggests that the representation of the lower visual field is expanded relative to that of the upper visual field (Maunsell and Van Essen, 1987). Such a retinotopic bias was not apparent in optical recording studies in owl monkey (Malonek et al., 1993); one possibility is that such a bias is species specific.

We tested whether human MT might have a lower field bias. Subjects were presented with moving random dots confined to either (1) the lower visual field, (2) the upper visual field, or (3) the entire visual field, in addition to control periods of uniform blank fields.

Here we do not address possible spatial (retinotopic) differences in activity produced by these three stimuli; they were not very apparent at this resolution anyway. Instead, we inferred the extent of cortical activation based on amplitude differences within the total area. Thus, the region-of-analysis was positioned over all of MT, based on responses to the (full field) movingversus-stationary stimuli.

fMRI amplitudes were essentially equal in upper versus lower visual field stimulations (see Fig. 13); this suggests that a lower field bias does not exist in the retinotopic representation of human MT. The full-field control stimulus produced significantly more activation than either upper or lower visual field stimulation (see Fig. 13). This confirms that activating a larger visual field representation (more cortical area) produces corresponding- ly larger fMRI amplitudes in MT. Levels of activation were indistinguishable in upper versus lower visual field sectors, irrespective of whether we tested with stimuli that extended all the way to the horizontal meridia, or "trimmed" visual field stimuli that systematically spared the horizontal meridia and slightly more than $20^{\circ}$ on either side of it (as shown in Fig. 13).

\section{Central versus peripheral retinotopy}

Empirical measurements strongly suggest that the cortical magnification factor in V1 varies approximately logarithmically with eccentricity, in both macaque (Daniel and Whitteridge, 1961; Hubel and Wiesel, 1969; Schwartz, 1980; Tootell et al., 1988a) and humans (Dobelle et al., 1979; IIorton and Hoyt, 1991). Evidence in subhuman primates suggests that the magnification factor in MT is similar to that in V1. However, in a related extrastriate area $(\mathrm{PO})$ the representation of the peripheral visual field is relatively expanded (Allman and Kaas, 1976).

Here we compared magnification factors in human V1 versus MT by presenting annular-shaped stimuli of equal-logarithmic width at different eccentricities. Moving random dot arrays were confined to annular- (donut-) shaped regions extending from either (1) $92-40^{\circ}$ or $(2) 2-4.6^{\circ}(\log$ difference $=0.36)$. Consistent with an approximately logarithmic magnification factor, such stimuli produce approximately equal-sized areas of activation in V1.

Due to its small size and diffuse retinotopy, an identical analysis could not be performed in human M'. However, its magnification factor was measured indirectly by sampling in all of visually activated MT. Following 30 presentations of central, peripheral, and full-field moving dot stimuli ( $40 \mathrm{sec}$ each) in five subjects, activity produced by the central versus peripheral stimuli was essentially equal (mean $=2.4$ vs $2.6 \%$ change, $\mathrm{SD}=$ $1.0 \%$ ) but less than that produced by full-field stimuli $(4.2 \%)$. The experimental results were thus similar to that shown in Figure 13. Since the two annular stimuli produced approximately equal activity, the magnification factor in human MT is presumably similar to that in V1.

\section{Discussion}

\section{Motion selectivity}

The motion-selectivity tests done earlier using the PET technique (Zeki et al., 1991; Watson et al., 1993) were quite similar to those done here; in fact, our initial aim was to simply replicate those results using the fMRI technique. In those limited comparisons, our motion-specific results match the PET data quite well. Comparing moving versus stationary stimuli, we found a distinctive motion-sensitive area ("MT") in the same cortical location as their "V5," based on Talairach coordinates. These coordinates are also generally consistent with those of an area specific for attention-to-motion that has been attributed to either MT or MST (Corbetta et al., 1990). We found additional motionselective areas in inferior parietal cortex, which match expectations from macaque visual cortex, and with Figure 4 from the PET studies of Watson et al. (1993).

The fMRI data has relatively high spatial and temporal resolution, and it allows unlimited scans of activity from each given subject to resolve progressively more detailed issues. All these factors made it possible to further characterize this single cortical area in unprecedented detail.

Because previous PET findings on MT are primarily pooled results from many subjects, we were unprepared to find significant variability in the motion selectivity of this area (see Fig. 
6). Although the moving/stationary ratios in MT ranged over almost a $\log$ unit, the motion selectivity in MT was robust enough so that we found no overlap between ratios in MT versus V1. Much of the variability was between individuals, rather than between sessions, or between hemispheres. To our knowledge, interindividual variation in motion selectivity has not been systematically assessed in monkey, but anecdotal observations are consistent with such interindividual differences. The contrast sensitivity of MT varied much less than did the motion selectivity data.

The present fMRI (see Fig. 7) and other functional measures (single units, optical recording studies) make it clear that MT can be activated by flickering stimuli, or the onset of stationary stimuli. This seems counter to the characterization of MT as motion selective. However, transient responses to the onset of stationary stimuli are compatible with some computational models of visual motion. One implication for brain mapping studies is that one should not be surprised to find MT activated by some stationary flickering stimuli, such as the flickering checkerboards or flickering LED goggles used commonly in PET and fMRI studies. Even if MT is not activated optimally by such stimuli, its cells are highly sensitive and quite active, potentially more so than its cortical neighbors.

The present study also demonstrated motion selectivity in some regions of inferior parietal cortex. Preliminary PET data from four subjects (Watson et al., 1993) also indicated a visual motion-selective area in human posterior parietal cortex, similar in location and size to that reported here. The motion selective areas here may also be related to a distinctive cytochrome oxidase staining pattern in posterior parietal cortex (area "PX"), in both macaque monkey and humans (Tootell and Taylor, 1994).

\section{Contrast sensitivity}

As in monkey MT, our fMRI data suggest that motion processing in human MT is linked with several other processing specializations, among them a higher contrast sensitivity. This has not been reported previously in human MT, and it is persuasive evidence for a dominant magnocellular bias. Thus, in general terms this also supports the notion of parallel visual pathways in man. This intersection of attributes also means that the functional isolation of area MT can be greatly enhanced by testing with a moving-stationary stimulus of low contrast.

The IMRI evidence indicates further that additional areas such as presumptive $\mathrm{V} 3$ and inferior parietal areas also have a high contrast sensitivity. By extrapolation from the macaque literature, these areas in man also have a dominant input from the magnocellular stream, so that a high contrast sensitivity in such areas is not surprising. Unlike the case in MT, however, presumptive area $\mathrm{V} 3$ shows very little motion bias.

\section{Equiluminant color motion}

Both human psychophysics (Anstis, 1970; Ramachandran and Gregory, 1978; Cavanagh et al., 1985; Gorea and Papathomas, 1989; Cavanagh and Anstis, 1991; Cavanagh, 1993) and macaque electrophysiology (Charles and Logothetis, 1989; Saito et al., 1989; Albright, 1991; Gegenfurtner et al., 1994) predict that MRI activation will decrease in human MT, when moving colorvarying gratings are equated in luminance.

To the extent that area MT can be modelled as an achromatic detector driven by a unimodal spectral sensitivity curve, our fMRI contrast response curves predict that it would decrease its response over a quite narrow range of luminance contrast (full width at half-height $= \pm 1-1.5 \%$, thus $2-3 \%$ luminance contrast) (see Fig. 10). However, such a hypothetical equiluminance "dip" should be decreased (filled in) by (1) any color-opponent inputs, (2) any rectified response to the borders of the colorvarying stimuli (Schiller and Colby, 1983, Saito et al., 1989; Schiller et al., 1990), and (3) any moving luminance artifacts in our stimuli.

On the other hand, any equiluminance dip should be widened (but again filled in) by (1) inaccuracies in our measurement of individual subject's equiluminance points, and/or (2) variation between equiluminance "null" points in individual magnocellular-dominated neurons.

The combination of all these factors made it difficult to predict its exact shape of any equiluminance dip, or even whether we should expect one at all. Given all possible factors that could erase an equiluminance dip, the robust presence of the observed dip suggests that much of the activity in MT/V5 is driven by achromatic inputs. MRI response amplitudes showed no significant decrease at equiluminance in area V1 of the same subjects.

This data supports the idea that the dip is related to the decreased perception of motion at equiluminance. Quantitatively, it is interesting to note that the amplitude of the dip ( $\sim 60 \%$ of the response to moving achromatic stimuli, otherwise identical) is only three times larger than the average response to truly stationary random dots in our moving-stationary tests $(\sim 20 \%$ of the response to moving achromatic stimuli, otherwise identical; Fig. 6), despite all the experimental and theoretical factors working against it.

In MT, the width of the equiluminance dip is approximately a $\log$ unit broader than what one would predict from our achromatic contrast gain measurements $(\sim 35 \%$ vs $2-3 \%$ respectively, full width at half-amplitude). It is known that the equiluminance "null" point for individual magnocellular- and MT cells in macaque ranges over approximately $0.4 \log$ units (Schiller and Colby, 1983; Saito et al., 1989), and this would be expected to widen the dip in any overall measure such as fMRI. Although this minimizes the apparent discrepancy, it does not eliminate it (see also Cavanagh and Anstis, 1991). We are currently studying this question in greater detail to see if the discrepancy is due to species differences (macaque single units versus human fMRI), to stimulus differences between studies, or to other factors.

\section{Retinotopy}

Two monkey genera have been thoroughly mapped: the Old World macaque (for review, see Felleman and Van Essen, 1991) and the New World Aotus (owl) monkey (for review, see Sereno and Allman. 1991; Kaas, 1993). Approximately 40 million years of evolution separates the macaque and owl monkeys, roughly the evolutionary period separating macaque from humans (Ciochon and Chiarelli, 1980). Other (unknown) evolutionary variables may be more critical than absolute time in predicting the extent of brain change between different primate species. Nevertheless, this evolutionary coincidence prompted us to look to comparisons between cortical maps in these two monkeys, to give us some idea of how much change to expect between cortical maps in humans versus monkeys.

In the owl and macaque monkey, areas V1, V2, VP, and MT (V5) are generally considered homologous (Burkhalter et al., 1986; Felleman and Van Essen, 1991; Sereno and Allman, 1991; Kaas, 1993). Satellite areas of MT (MST, FST) may also be homologous. Areas DM versus V3, and DL versus V4, are ar- 
guably homologous. The many remaining cortical visual areas in macaque and owl monkey are not obviously comparable. To be fair, less is known about such areas, but the generality nevertheless emerges that it is the lower-tier areas that are evolutionarily conserved, and the higher-tier areas more variable across evolution. Anatomical (Tootell et al., 1985) and comparative (e.g., Sereno and Allman, 1991; Kaas, 1993) evidence is consistent with this generality.

In humans we might thus expect to find areas V1, V2, VP, MT, and perhaps V3, among others. Most of these areas are highly or somewhat retinotopic, and the retinotopic areas border adjoining cortical areas along the representation of either the horizontal or vertical meridian. Previous anatomical (Clarke and Miklossy, 1990; Horton and Hoyt, 1991) and functional (Schneider et al., 1993) studies aimed at defining human cortical areas have been based on such reasoning.

Using retinotopically specific, pie-shaped wedges centered along either vertical or horizontal meridia, we were able to activate the border region between presumptive areas $\mathrm{V} 1$ versus V2, V2 versus V3, V3 versus V3A, and V2 versus VP (see Fig. 2). Since there is a great deal of variability in the location of human cortical areas (Stensaas et al., 1974; Talairach and Tournoux, 1988; Watson et al., 1993), it was only by first labeling the borders between these areas that we were able to confidently characterize each area's behavior in subsequent fMRI tests. Such stimuli offer a quick and valuable tool for distinguishing cortical areas.

Using retinotopically specific stimuli, human area MT was not very retinotopic: we were not able to distinguish activation along vertical versus horizontal meridia, nor upper versus lower visual fields. This was not particularly surprising, since macaque MT is also not very retinotopic (Gattas and Gross, 1981; Van Essen et al., 1981; Desimone and Ungerleider, 1986; Albright and Desimone, 1987; Maunsell and Van Essen, 1987).

In human MT, however, we were able to make rough measurements of the degree of interhemispheric overlap (half-amplitude across the vertical meridian $=\sim 15^{\circ}$ ) in MT. Realistically, this value may be slightly inflated by partial volume sampling with activity in adjacent areas such as MST and FST; in macaque these areas are known to have larger receptive fields and more vertical meridian sharing than does MT. However, given only minor technical improvements (e.g., collection of data at higher resolution, use of different sequences), this approach could furnish indirect estimates of the average receptive field size and hierarchical position in most cortical areas in human visual cortex, including those that appear less retinotopic by othcr critcria.

In human MT, we were also able to indirectly measure the magnification factor, and to test for the presence of a lower visual field bias, as described in macaque (Maunsell and Van Essen, 1987).

\section{Overall}

Converging CMRI data from numerous different visual tests reveals an area in human visual cortex almost functionally indistinguishable from macaque MT. Several different stimuli activated the same cortical region, within and between scanning sessions. Results from this study emphasize that at least some kinds of detailed functional tests can be carried out on welldefined cortical areas, complementing psychophysical information obtained from the whole person.

This study was designed initially to test whether (and to what extent) the relatively new fMRI technique could be used to map the functional organization of human extrastriate visual cortex. Because a great deal is known about monkey MT, and because this area appears to be identifiable and relatively similar across a wide range of primate species, one recurring theme here was to simply test whether human MT behaved like monkey MT. The positive results described here validate the fMRI technique as well as our expectations about the evolution of extrastriate visual cortical areas. These results thus also set the stage for a more confident fMRI exploration of currently unknown human cortical visual areas, using more imaginative stimuli.

\section{References}

Albright TD (1984) Direction and orientation selectivity of neurons in visual area MT of the macaque. J Neurophysiol 52:1106-1130.

Albright TD (1989) Centrifugal directional bias in the middle temporal visual area (MT) of the macaque. Visual Neurosci 2:177-188.

Albright TD (1991) Color and the integration of motion signals. Trends Neurosci 14:266-269.

Albright TD (1993) Form-cue invariant motion processing in primate visual cortex. Science 255:1141 1143.

Albright TD, Desimone R (1987) Local precision of visuotopic organization in the middle temporal area (MT) of the macaque. Exp Brain Res 65:582-592.

Allman JM, Kaas JH (1971a) Representation of the visual field on the medial wall of occipital-parietal cortex in the owl monkey. Science 191:572-575.

Allman JM, Kaas JH (1971b) A representation of the visual field in the caudal third of the middle temporal gyrus of the owl monkey (Aotus trivirgatus). Brain Res 31:85-105.

Allman JM, Kaas JH, Lane RH (1973) The middle temporal visual area (MT) in the bushbahy (Galago senegalensis). Brain Res 57:197202.

Andersen RA, Essick GK, Siegel RM (1987) Neurons of area 7 activated by both visual stimuli and oculomotor behavior. Exp Brain Res 67:316-322.

Andersen RA, Asanuma C, Essick G, Siegal RM (1990) Cortico-cortical connections of anatomically and physiologically defined subdivisions within the inferior parietal lobule. J Comp Neurol 296:65113.

Anstis SM (1970) Phi movement as a subtraction process. Vision Res 10:1411-1430.

Baker JR, Hoppel BE, Stern EE, Kwong KK, Weisskoff RM, Rosen BR (1993) Dynamic functional imaging of the complete human cortex using gradient-echo and asymmetric spin-echo echo-planar magnetic resonance imaging. 12th Annu Proc Soc Magn Reson Med, p 1400.

Bandettini PA, Wong EC, Hinks RS, Tikofsky RS, Hyde JD (1992) Time course EPI of human brain function during task activation. Magn Reson Med 25:390-397.

Bandettini PA, Wong EC, Jesmanowicz A, Hinks RS, Hyde JS (1993) Simultaneous mapping of activation-induced delta R2 ${ }^{*}$ and delta R2 in the human brain using a combined gradient-echo and spin-echo EPI pulse sequence. 12th Annu Proc Soc Magn Reson Med, pp 169.

Belliveau JW, Kennedy DN Jr, McKinstry RC, Buchbinder BR, Weiskoff RM, Cohen MS, Vevea JM, Brady TJ, Rosen BR (1991) Functional mapping of the human visual cortex by magnetic resonance imaging. Science 254:716-719.

Belliveau JW, Kwong KK, Kennedy DN, Baker JR, Stern CE, Benson R, Chesleer DA, Weiskoff RM, Cohen MS, Tootell RBH, Fox PY, Brady TJ, Rosen BR (1992) Magnetic resonance imaging mapping of brain function: human visual cortex. Invest Radiol 27:S59-S65.

Born RT, Tootell RBH (1992) Segregation of global and local motion processing in primate middle temporal visual area. Nature 357:497499.

Boussaoud D, Ungerleider LC, Desimone R (1990) Pathways for motion analysis: cortical connections of the medial superior temporal and fundus of the superior temporal visual areas in the macaque. $J$ Comp Neurol 296:462-495.

Burkhalter A, Bernardo KL (1989) Organization of cortico-cortical connections in human visual cortex. Proc Natl Acad Sci USA 86: 1071-1075.

Burkhalter A, Felleman DJ, Newsome WT, Van Essen DC (1986) An- 
atomical and physiological asymmetries related to visual areas $\mathrm{V} 3$ and VP in macaque extrastriate cortex. Vision Res 26:63 80.

Cavanagh $P$ (1993) The perception of form and motion. Curr Opinion Neurobiol 3:177-182.

Cavanagh P, Anstis S (1991) The contribution of color to motion in normal and color-deficient observers. Visual Res 31:2109-2148.

Charles ER, Logothetis NK (1989) The responses of middle temporal neurons to isoluminant colors. Invest Ophthalmol Visual Sci 30:427.

Ciochon RL, Chiarelli AB (1980) Evolutionary biology of the New World monkeys and continental drift. New York: Plenum.

Clarke S, Miklossy J (1990) Occipital cortex in man: organization of callosal connections, related myelo- and cytoarchitecture, and putative boundaries of functional visual areas. J Comp Neurol 298:188214.

Corbetta M, Meizen FM, Dobmeyer S, Shulman GL, Petersen SE (1990) Attentional modulation of neural processing of shape, color and velocity in humans. Science 248:1556-1559.

Crick F, Jones E (1993) Backwardness of human neuroanatomy. Nature 361:109-110.

Damasio A, Tranel D, Damasio H (1990) Facial agnosia and the neural substrates of memory. Annu Rev Neurol 13:9-109.

Daniel PM, Whitteridge D (1961) The representation of the visual field on the cerebral cortex in monkeys. J Physiol (Lond) 159:203-221.

DeBruyn EI, Casagrande VA, Beck PD, Bonds AB (1993) Visual resolution and sensitivity of single cells in the primary visual cortex (V1) of a nocturnal primate (bush baby): correlations with cortical layers and cytochrome oxidase patterns. J Neurophysiol 69:3-18.

Derrington AM, Lennie P (1984) Spatial and temporal contrast sensitivities of neurons in lateral geniculate nucleus of macaque. J Physiol (Lond) 357:219-240.

Desimone R, Ungerleider LG (1986) Multiple visual areas in the caudal superior temporal sulcus of the macaque. J Comp Neurol 248: 164-189.

Desimone R, Ungerleider LG (1989) Neural mechanisms of visual processing in monkeys. In: Handbook of neuropsychology, Vol 2 (Boller F, Grafman J, eds), pp 267-299. New York: Elsevier.

DeValois RL, Morgan HC, Polson MC, Mead WR, Hull EM (1974a) Psychophysical studies of monkey vision. I. Macaque luminosity and color vision tests. Vision Res 14:53-67.

DeValois RL, Morgan HC (1974b) Psychophysical studies of monkey vision. II. Squirrel monkey wavelength and saturation discrimination. Vision Res 14:69-73.

DeValois RL, Morgan H, Snodderly DM (1974c) Psychophysical studies of monkey vision. III. Spatial luminance contrast sensitivity tests of macaque and human observers. Vision Res 14:75-81.

DeYoe EG, Van Essen DC (1985) Segregation of efferent connections and receptive field properties in visual area V2 of the macaque monkey. Nature 317:58-61.

DeYoe FG, Van Fssen DC (1988) Concurrent processing streams in monkey visual cortex. Trends Neurosci 11:219-226.

Dobelle WH, Turkel J, Henderson DC, Evans JR (1979) Mapping the representation of the visual field by electrical stimulation of human visual cortex. Am J Ophthalmol 88:727-735.

Dubner R, Zeki SM (1971) Response properties and receptive fields of cells in an anatomically defined region of the superior temporal sulcus in the monkey. Brain Res 35:528-532.

Felleman DJ, Kaas JH (1984) Receptive-field properties of neurons in middle temporal visual area (MT) of owl monkeys. J Neurophysiol 52:488-513.

Felleman DJ, Van Essen DC (1991) Distributed hierarchical processing in the primate cerebral cortex. Cereb Cortex 1:1-47.

Fiorani M Jr, Gattas R, Rosa MGP, Sousa APB (1989) Visual area MT in the Cebus monkey: location, visuotopic organization and variability. J Comp Neurol 287:98-118.

Fisel CR, Ackerman JL, Buxton RB, Garrido L, Belliveau JW, Rosen BR, Brady TJ (1991) MR contrast due to microscopically heterogeneous magnetic susceptibility: numerical simulations and applications to cerebral physiology. Magn Reson Med 17:336-347.

Fitzpatrick D, Lund JS, Blasdel GG (1985) Intrinsic connections of macaque striate cortex: afferent and efferent connections of lamina 4C. J Neurosci 5:3329-3349.

Frahm J, Merboldt KD, Hanicke W (1993) Functional MRI of human brain activation at high spatial resolution. Magn Reson Med 29:139144.

Gattas R, Gross CG (1981) Visual topography of striate projection zone
(MT) in posterior superior temporal sulcus of the macaque. J Neurophysiol 16:621-638.

Gegenfurtner KR, Kiper DC, Beusmans JMH, Caradini M, Zaidi Q, Movshon JA (1994) Chromatic properties of neurons in macaque MT. Visual Neurosci 11:455-466.

Goodale MA, Milner AD (1992) Separate visual pathways for perception and action. Trends Neurosci 15:20-25.

Gorea A, Papathomas 'I'V (1989) Motion processing by chromatic and achromatic pathways. J Opt Soc Am A6:590-602.

Graziano MSA, Andersen RA, Snowden RJ (1993) Tuning of MST neurons to spiral motions. J Neurosci, in press.

Hawken MJ, Parker AJ (1984) Contrast sensitivity and orientation selectivity in lamina IV of the striate cortex of old world monkeys. Exp Brain Res 54:367-372.

Hawken MJ, Parker AJ, Lund JS (1988) Laminar organization and contrast sensitivity of dircction-selective cells in the striate cortex of the owl world monkey. J Neurosci 8:3541-3548.

Hawken MJ, Gegenfurtner KR, Tang C (1994) Contrast dependence of colour and luminance motion mechanisms in human vision. Nature $367: 268-270$

Hockfield S, Tootell RBH, Zaremba S (1990) Molecular differences among neurons reveal an organization of human visual cortex. Proc Natl Acad Sci 87:3027-3031.

Horton JC, Hoyt WF (1991a) The representation of the visual field in human striate cortex. Arch Ophthalmol 109:816-824.

Horton JC, Hoyt WF (1991b) Quadrantic visual field defects. A hallmark of lesions in extrastriate (V2/V3) cortex. Brain 114:1703-1718.

Hubel DH, Livingstone ML (1968) Receptive fields and functional architecture of monkey striate cortex. J Physiol (Lond) 195:215-243.

Hubel DH, Livingstone MS (1990) Culor and contrast sensitivity in the lateral geniculate body and primary visual cortex of the macaque monkey. J Neurosci 10:2223-2237.

Hyvarinen J (1981) Regional distribution of functions in parietal association area 7 of the monkey. Brain Res 206:287-303.

Jacobs GH (1977a) Visual capacities of the owl monkey (Aotus trivirgatus). I. Spectral sensitivity and color vision. Vision Res 17:811820.

Jacobs GH (1974b) Visual capacities of the owl monkey (Aotus trivirgatus). II. Spatial contrast sensitivity. Vision Res 17:821-825.

Jiang A, Kennedy D, Woods R, Baker J, Tootell R, Kwong K, Weiskoff R, Belliveau J, Brady T, Rosen B (1994) Motion detection and correction in functional MRI. 13th Annu Proc Soc Magn Res Med, in press.

Kaas JH (1993) The organization of visual cortex in primates: problems, conclusions, and the use of comparative studies in understanding the human brain. In: Functional organisation of the human visual cortex (Gulyas B, Ottoson D, Roland PE, eds), pp 1-12. New York: Pergamon.

Kaas JH, Garraghty PE (1991) Hierarchical, parallel, and serial arrangements of sensory cortical areas: connection patterns and functional aspects. Curr Biol 1:248-251.

Kaplan E, Shapley RM (1982) X and Y cells in the lateral geniculate nucleus of macaque monkeys. J Physiol (Lond) 330:125-143.

Krubitzer LA, Kaas JH (1990) Cortical connections of MT in four species of primates: areal, modular and retinotopic patterns. J Neurosci 5:165-204.

Kwong KK, Belliveau JW, Chesler DA, Goldberg IE, Weiskoff RM, Poncelet BP, Kennedy DN, Hoppel BE, Cohen MS, Turner R, Rosen $B$, Brady TJ (1992) Dynamic magnetic resonance imaging of human brain activity during primary sensory stimulation. Proc Natl Acad Sci USA 89:5675-5679.

Kwong KK, Chesler DA, Zuo CS, Boxerman JL, Baker JR, Chen YC, Stern CE, Weiskoff RM, Rosen BR (1993) Spin-echo studies (T2, T1) for functional MRI. 12th Annu Proc Soc Magn Reson Med, pp 172.

Lagae L, Maes H, Raiguel S, Xiao D-K, Orban GS (1994) Responses of macaque STS neurons to optic flow components: a comparison of areas MT and MST. $\mathbf{J}$ Neurophysiol 71: in press.

Livingstone M, Hubel DH (1988) Segregation of form, color, movement and depth: anatomy, physiology and perception. Science 240 : 740-749.

Lueck CJ, Zeki S, Friston KJ, Dieber M-P, Cope P, Cunningham VJ, Lammertsma AA, Kennard C, Frackowiak RSJ (1989) The colour centre in the cerebral cortex of man. Nature 340:386-389.

Lund JS, Boothe RG (1975) Interlaminar connections and pyramidal 
neuron organization in the visual cortex, area 17, of the macaque monkey. J Comp Neurol 159:305-334.

Lund JS, Lund RD, Hendrickson A, Brunt AH, Fuchs AF (1976) The origin of efferent pathways from the primary visual cortex, area 17 of the macaque monkey as shown by retrograde transport of horseradish peroxidase. J Comp Neurol 164:287-304.

Malonek D, Tootell RBH, Grinvald A (1993) Optical imaging of orientation, direction and retinotopic organization in area MT of the owl monkey. Soc Neurosci Abstr 19:1500.

Martin KAC (1988) From enzymes to visual perception: a bridge too far? Trends Neurosci 11:380-387.

Maunsell JHR (1987) Physiological evidence for two visual subsystems. In: Matters of intelligence (Vaina L, ed), pp 59-87. Dordrecht: Reidel.

Maunsell JHR, Newsome WT (1987) Visual processing in monkey extrastriate cortex. Annu Rev Neurosci 10:363-401.

Maunsell JHR, Van Essen DC (1983a) Anatomical connections of the middle temporal visual area (MT) and their relationship to a cortical hierarchy in the macaque monkey. J Neurosci 3:2563-2586.

Maunsell JHR, Van Essen DC (1983b) Functional properties of neurons in middle temporal visual area of the macaque monkey. I. Selectivity for stimulus direction, speed, and orientation. J Neurophysiol 49:1127-1147.

Maunsell JHR, Van Essen DC (1987) Topographic organization of the middle temporal visual area in the macaque monkey: representational biases and the relationship to callosal connections and myeloarchitectonic boundaries. J Comp Neurol 266:535-555.

Merigan WH, Maunsell JHR (1993) How parallel are the primate visual pathways? Annu Rev Neurosci 16:369-402.

Motter BC, Mountcastle VB (1981) The functional properties of the light-sensitive neurons of the posterior parietal cortex studied in waking Inonkeys: foveal sparing and opponent vector organization. J Neurosci 1:3-26.

Press WH, Flanner BP, Teukolsky SA, Veterling WT (1988) Numerical recipes in $\mathrm{C}$ : the art of scientific computing. New York: Cambridge UP.

Purpura K, Kaplan E, Shapley RM (1988) Background light and the contrast gain of primate $\mathrm{P}$ and $\mathrm{M}$ retinal ganglion cells. Proc Natl Acad Sci USA 85:4534-4537.

Ramachandran VS, Gregory R (1978) Does colour provide an input to human motion perception? Nature 275:55-56.

Rodman HR, Albright TD (1989) Single-unit analysis of pattern-motion selective properties in the middle temporal visual area (MT). Exp Brain Res 75:53-64.

Saito H, Tanaka K, Isono H, Yasuda M, Mikami A (1989) Directionally selective response of cells in the middle temporal ared (MT) of the macaque monkey to the movement of equiluminous opponent color stimuli. Exp Brain Res 75:1-14.

Schiller PH, Colby CL (1983) 'I'he response of single cells in the lateral geniculate nucleus of the rhesus monkey to color and luminance contrast. Vision Res 23:1631-1641.

Schiller PH, Logothetis N, Charles E (1990) The role of the coloropponent and broadband channels in vision. Visual Neurosci 5:321346.

Schneider W, Noll DC, Cohen JD (1993) Functional topographic mapping of the cortical ribbon in human vision with conventional MRI scanners. Nature 365:150-153.

Schwartz EL (1980) Computational anatomy and functional architecture of striate cortex: a spatial mapping approach to perceptual coding. Vision Res 20:645-669.

Sclar G, Maunsell JHR, Lennie P (1990) Coding of image contrast in central visual pathways of the macaque monkey. Vision Res 30:110.

Sereno MI, Allman JM (1991) Cortical visual areas in mammals. In: The neural basis of visual function (Leventhal $A G$, ed), pp 160-172. London: Macmillan.

Shapley R, Perry VH (1986) Cat and monkey retinal ganglion cells and their visual functional roles. Trends Neurosci 9:229-235.

Shapley R, Kaplan E, Soodak R (1981) Spatial summation and contrast sensitivity of $\mathrm{X}$ and $\mathrm{Y}$ cells in the lateral nucleus of the macaque. Nature 292:543-545.

Shipp S, Zeki SM (1985) Segregation of pathways leading from area V2 to areas V4 and V5 of macaque monkey visual cortex. Nature 315:322-325.
Stcnsaas SS, Eddington DK, Dobclle WH (1974) Topography of the human visual cortex. J Neurosurg 40:747-751.

Stoner GR, Albright TD (1992) Motion coherency rules are form-cue invariant. Visual Res 32:465-475.

Stuart A, Ord JK (1991) Kendall's advanced theory of statistics. New York: Oxford UP.

Talairach J, Tournoux P (1988) Co-planar stereotaxic atlas of the human brain. New York: Thieme.

Tanaka K, Saito H (1989) Analysis of motion of the visual field by direction, expansion/contraction and rotation cells clustered in the dorsal part of the medial superior temporal area of the macaque monkey. J Neurophysiol 62:626-641

Tootell RBH, Taylor JB (1994) Anatomical evidence for MT/V5 and other cortical visual areas in man. Cereb Cortex, in press.

Tootell RBH, Hamilton SL, Silverman MS (1985) Topography of cytochrome oxidase activity in owl monkey cortex. J Neurosci 5:27862800.

Tootell RBH, Switkes E, Silverman MS, Hamilton SL (1988a) Functional anatomy of macaque striate cortex. II. Retinotopic organization. J Neurosci 8:1531-1568.

Tootell RBH, Hamilton SL, Switkes E (1988b) Functional anatomy of macaque striate cortex. IV. Contrast and magno-parvo streams. J Neurosci 8:1594-1609.

Tootell RBH, Kwong KK, Belliveau JW, Baker JR, Stern CE, Hockfield SJ, Breiter H, Born R, Benson R, Brady TJ, Rosen BR (1993a) Mapping human visual cortex: evidence from functional MRI and histology. Invest Ophthalmol Visual Sci [Suppl].

Tootell RBH, Kwong KK, Belliveau JW, Baker JR, Stern CE, Savoy RL, Breiter H, Born R, Benson R, Brady TJ, Rosen BR (1993b) Functional MRI (fMRI) evidence for MT/V5 and associated visual cortical areas in man. Twenty-third Annual Meeting of the Society for Neurosciences.

Turner R, Jezzard P, LeBhan D, Prinster A (1993) Contrast mechanisms and vessel size effects in BOLD contrast functional neuroimaging. 12th Annu Proc Soc Magn Reson Med, pp 173.

Vaina L (1989) Selective impairment of visual motion interpretation following lesions of the right occipito-parietal area in humans. Biol Cybern 61:347-359.

Van Essen DC, Maunsell JHR, Bixby JL (1981) The middle temporal visual area in the macaque: myelnarchitecture, connections, functional properties and topographic organization. J Comp Neurol 199:293326.

Van Essen DC, Anderson CH, Felleman DJ (1992) Information processing in the primate visual system: an integrated systems perspective. Science 255:419-423.

Walson JDG, Myers R, Frackowiak RSJ, Hajilal JV, Woods RP, Mazziota JC, Shipp S, Zeki S (1993) Area V5 of the human brain: evidence from a combined study using positron emission tomography and magnetic resonance imaging. Cereb Cortex 3:79-94.

Weiskoff RM, Boxerman JL, Chun S, Zuo S, Rosen BR (1993) Endogenous susceptibility contrast: principles of relationship between blood oxygenation and MR signal change. In: Functional MRI of the brain: a workshop, pp 103-110.

Wismer GL, Buxton RB, Rosen BR, Fisel CR, Oot RF, Brady TJ, Davis KR (1988) Susceptibility induced MR line broadening: applications to brain iron mapping. J Comput Assist Tomogr 12:259-265.

Woods RP, Cherry SR, Mazziotta JC (1992) Rapid automated algorithm for aligning and reslicing PET images. J Comput Assist Tomogr 16:620-633.

Yoshioka T, Levitt JB, Lund JS (1993) Anatomical basis for channel interactions in macaque cortical visual area V1. Invest Ophthalmol Visual Sci [Suppl] 34:1173.

Zeki SM (1980) 'Ihe response properties of cells in the middle temporal area (area MT) of owl monkey visual cortex. Proc R Soc Lond [Biol] 207:239-248.

Zeki S (1990) A century of cerebral achromatopsia. Brain 113:17211777.

Zeki S (1991) Cerebral akinetopsia (visual motion blindness): a review. Brain 114:811-824.

Zeki S, Shipp S (1988) The functional logic of cortical connections. Nature 335:311-317.

Zeki S, Watson JDG, Lueck CJ, Friston KJ, Kennard C, Frackowiak RSJ (1991) A direct demonstration of functional specialization in human visual cortex. J Neurosci 11:641-649. 